\title{
A Working Prototype Using DS18B20 Temperature Sensor and Arduino for Health Monitoring
}

\author{
Ramesh Saha $^{1}$ [D Suparna Biswas ${ }^{2}$ [D $\cdot$ Satyajit Sarmah ${ }^{1} \cdot$ Sushanta Karmakar ${ }^{3} \cdot$ Pranesh Das $^{1}$
}

Received: 12 December 2020 / Accepted: 16 December 2020 / Published online: 12 January 2021

(c) The Author(s), under exclusive licence to Springer Nature Singapore Pte Ltd. part of Springer Nature 2021

\begin{abstract}
Due to the successful emergence of internet of things, sensor-based real-time health monitoring is getting popularized. A usable health-monitoring system is required for prolonged monitoring of the patient with reduced cost. This paper describes a working prototype system for real-time health-monitoring system using DS18B20 temperature sensor, Arduino Nano with micro-controller ATmega328 where Zigbee module is used for wireless communication. In this prototype sensor data gets acquired and analyzed to give proper feedback to the patient with or without mobility support at indoor. The sensor vitals are collected and sent to the computing device using shielded cable and ZigBee, i.e., through wired and wireless communication, respectively. Analysis of patient vitals based on medical definitions gives patient's real-time health condition so that if condition is not normal, then timely preventive measures can be taken to avoid further complication. Per user data can be saved in the system database for further reference.
\end{abstract}

Keywords Health monitoring $\cdot$ Temperature sensor $\cdot$ Arduino $\cdot$ Zigbee $\cdot$ Prototype $\cdot$ Mobility

\section{Introduction}

Internet of things (IoT) [1-5] has changed our daily living with its different applications. The concept of the IoT reflects a connection in a set of any time, anything, anyplace, any network, and any services. IoT moves to the up and coming age of advancements that can affect an entire

Suparna Biswas

mailtosuparna@gmail.com

Ramesh Saha

ramesh1saha@gmail.com

Satyajit Sarmah

ss@gauhati.ac.in

Sushanta Karmakar

sushantak@gmail.com

Pranesh Das

pranesh.das@gmail.com

1 Department of Information Technology, Gauhati University, Guwahati, Assam, India

2 Department of Computer Science and Engineering, Maulana Abul Kalam Azad University of Technology, West Bengal, Kolkata, West Bengal, India

3 Department of Computer Science, IIT Guwahati, Guwahati, Assam, India human life. IoT provides a wide range of applications such as smart city, waste management, traffic congestion, emergency services and structure of health, industrial control, surveillance and healthcare. Smart and remote healthcare is the most on demand application of IoT. It has many potential applications to give rise to healthcare applications like remote health monitoring, a fitness program for home-based health-monitoring, chronic disease detection, and older people care, etc. IoT based healthcare service utilizes wireless body area network (WBAN) [6-8] which is a subset of wireless sensor network (WSN) $[9,10]$. Usage of WBAN in healthcare increases the QoS and reduces the costs with enhanced usability. Initially, IoT based WBANs $[6,7,11]$ are one of the most desirable technology for building smart health monitoring for the patient. The application of healthcare monitoring using WBAN consists of a specified number of heterogeneous sensor nodes. This sensor node is capable of sensing one or more physiological parameters of the human body, e.g.,--blood pressure, the heart rate, electrocardiograms (ECG) electromyograms (EMG) [12], muscular activity and body temperature, etc. Then acquired signals are transmitted to the sink or coordinator of the WBAN for further processing $[12,13]$. The sink or coordinator is equipped with sufficient resources of this activity. It has 
more processing power and transmit to the medical server for further or future processing through internet.

Tiny sensors in WBAN are incorporated into fabrics or attached on other wearable substances or implanted in the human body for sensing body vitals. These have many advantages such as low power, low cost, multifunctional sensor nodes that are modest in size and communicate with each other over a short distance, which do not interrupt (or restrict) users' normal activity. With the help of WBAN, a user can be monitored at anytime, anywhere, and for any duration. In the WBAN-Based health-monitoring architecture is three-layer architecture $[6,7,14,15]$ shown in Fig. 1 $[3,5,6]$. Tier 1: enclose a set of small, smart sensors that are wearable or implanted in the human or patient body. Sensor nodes simply collects the vital signals from the patient. Tier 2: there is a WBAN architecture Gateway, i.e., Sink, which collected the vital signal from the sensors and process them. Tier 3: Gateway or Sink connected to the medical server through the internet. The architecture of WBAN is shown in Fig. 1 [7].

In this paper, we develop a working prototype of WBAN using a temperature sensor. Human or patient body temperature is transferred to the central control unit (CCU) of microcontroller-based arduino both wired and wirelessly over a short distance. The CCU is placed in a nearby location that is decided based on system's ability to support maximum mobility and flexibility of the patient for monitoring. Organization of the paper is as follows: "Related work" describes the related work, "Motivation and contribution" illustrates motivation of the work, the next section discusses the methodology and implementation of our experiment, all finding and results are summarized in "Experimental results", finally results are concluded in "Conclusion".

\section{Related Work}

A number of relevant research papers are described in this section followed by a comprehensive summary table highlighting comparative view based on their contributions.

Valerie Gay and Peter Leijdekkers [1] has proposed a prototype regarding personnel heart monitoring using a smartphone. The author used a physical wireless sensor a smartphone to monitor the high-risk cardiac patient. Using this prototype, a person or patient can understand the high risk of the heath, and the smartphone can automatically send an alert to the caregiver or call the ambulance.

Chris A. Otto et al. [2] proposed a model. In this proposed model, WBAN connected to the home health server. The home server integrated into the predefined database and information further sent to the medical server for further inspection. This prototype is used for cardiac rehabilitation patients or older people and gave proper guidance.

Ahmed Baraka et al. [3] investigated a framework using WBAN for measurement of electrocardiogram (ECG) and human movement kinematics. Authors believed that it provided the system can handle easily continuous health monitoring for the patient. In these framework developed a
Fig. 1 The architecture of the WBAN

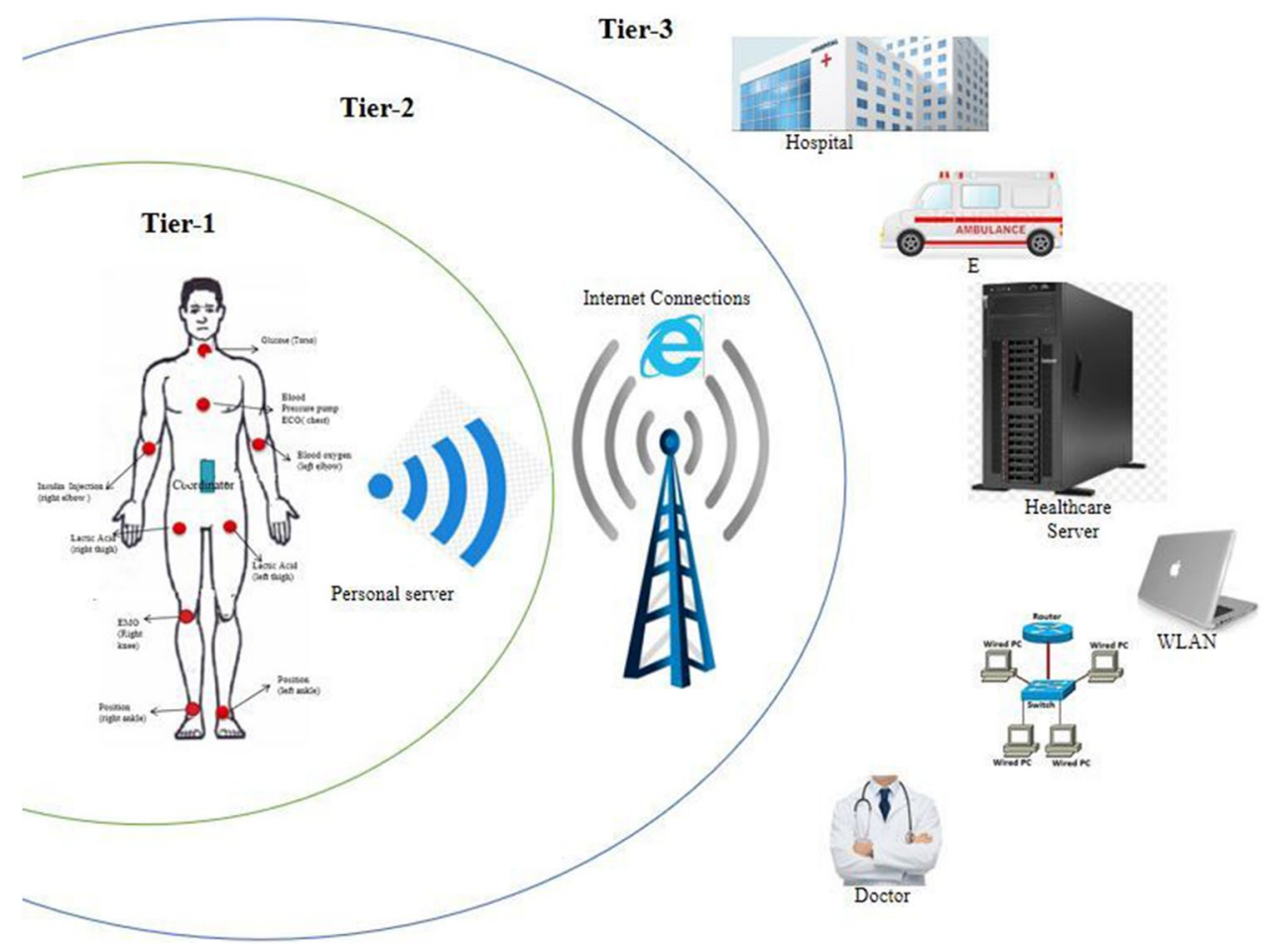


software enable system which collected data from WBAN sensors and sent to the medical server for a physician can monitor the patient more efficiently.

Marius Roşu and Sever Paşca [4] has been proposed a real-time remote healthcare solution for patients. It can surveillance the patient anytime from anywhere. Here the author used a programmable ECG sensor with wire able wireless body/personal area network (WWBAN) and sent data to the medical server to check the condition of the patient. In this paper, using ZigBee technology and low power wireless sensor with local processing capabilities to achieve high mobility and flexibility of the patient. Author added here if the emergency condition of the patient happens then the programmable ECG sensor automatically sends an alert to the caregiver.

Muhammad Udin Harun Al Rasyid et al. [5] proposed an e-health sensor system that can be used to read vital health signals and store in the database server-here used body temperature sensor and a blood oxygen sensor. In these systems, vital signals collected from sensors and sensors data reading to a desktop application as well as store data in the database and display the data via a website in the form of report that can be accessed remotely.

Benjamin Kommey et al. [6] proposed a patient medical emergency alert system (PMEAS). It uses two sensors: temperature sensor and heart rate sensor as a hardware unit and android application. In that system, collected patient vital signal getsdisplayed on an LCD screen and sends to the android device via bluetooth and managed by the apps. If any abnormal condition seems to the system, an alert is sent to the caregiver through email or SMS in a confidential manner. This system also forms a graph to help determine the state of health of the user.

Ying Zhang and Hannan Xiao [7] proposed a Bluetooth based sensor network system which remotely monitors patient physiological signal. Authors focus on implementation issues and describe these system architecture using heart activity sensors. The proposed network system is developed using intelligent physiological sensor nodes, intelligent Bluetooth technology, hardware and software. Authors gave a solution for onboard signal processing.

Young-Dong Lee and Wan-Young Chung [8] developed a smart shirt to monitor patient's health continuously based on WBAN technology. The smart shirt is attached to the ECG and acceleration sensor. The shirt mainly collected health data from patients' bodies as electrodes and transmitted to base station from the ad-hoc network using 802.15.4 communication standard.

Adrian Burns et al. [9] have been applying new sensing technology to the emerging global healthcare system. Authors developed new approaches for continuous health monitoring using SHIMMER ${ }^{\mathrm{TM}}$.
Chih-Ming Chen [10] developed a model to provide long medical treatment which is web-based. The proposed system can be used to study and analyze a patient's condition remotely.

Navya and Murthy [14] proposed a health network model using ZigBee. Here patient health physiological data of the patients are monitored and the output of the sensors data is sent to the personal computer. It is a remote health network system that can be a data store for future use. In that system, sensors are used to measure temperature, heart rate, and fall monitoring of the patient using ZigBee. Authors also proposed a solution for patient monitoring when patient data crosses the threshold value, and the personal computer sends a message to the mobile phone of the caregiver.

Prajakta A. Pawar [14] presented a system which is used to monitor physical parameter of the human body like a heartbeat. This system can be used in a rural area or remote area; by using GSM, module patients can be transmitted data to the doctor mobile. This system is an appropriate homebased effective health-monitoring system that can be monitored elder people.

Amna Abdullah et al. [12] proposed a field-tested realtime health monitoring using a PDA device. The main objective of the proposed model is to study the patient's health condition regularly. Authors proposed system can measure or monitoring patient-important physiological data and is collected by the sensors and transmitted it to the mobile android based apps, besides this system also able to generate an alarm message or confidential email if patient health in critical condition and send it to the healthcare professional for necessary medical advice.

Johan Wannenburg and Reza Malekian [13] designed and implemented a mobile health-monitoring system. The system capable of measuring vital physiological signals of the patient, interpret the collected signal, and monitoring. In some cases, abnormal conditions occurred, then it detected and sent to a medical team for analysis. The system is an analysis and investigation of various biological extraction methods. All the required parameters were measured accurately by following medical standards. The system should be providing accurate feedback to the user and successfully identify the medical problem and send a notification to a doctor for prescribing the next step.

Kumar and Pallikonda Rajasekaran [15] proposed a model for monitoring patients' condition by Raspberry Pi. The author implemented a simple healthcare application using a temperature sensor for body temperature, ECG for heart bit, and proximity for movement. These sensors send the vital signal to the Raspberry $\mathrm{Pi}$, and sensor data can be monitored in the monitored screen of the computer by using Raspberry Pi, which acts as a Linux PC as well as anywhere in the world using the Internet. 


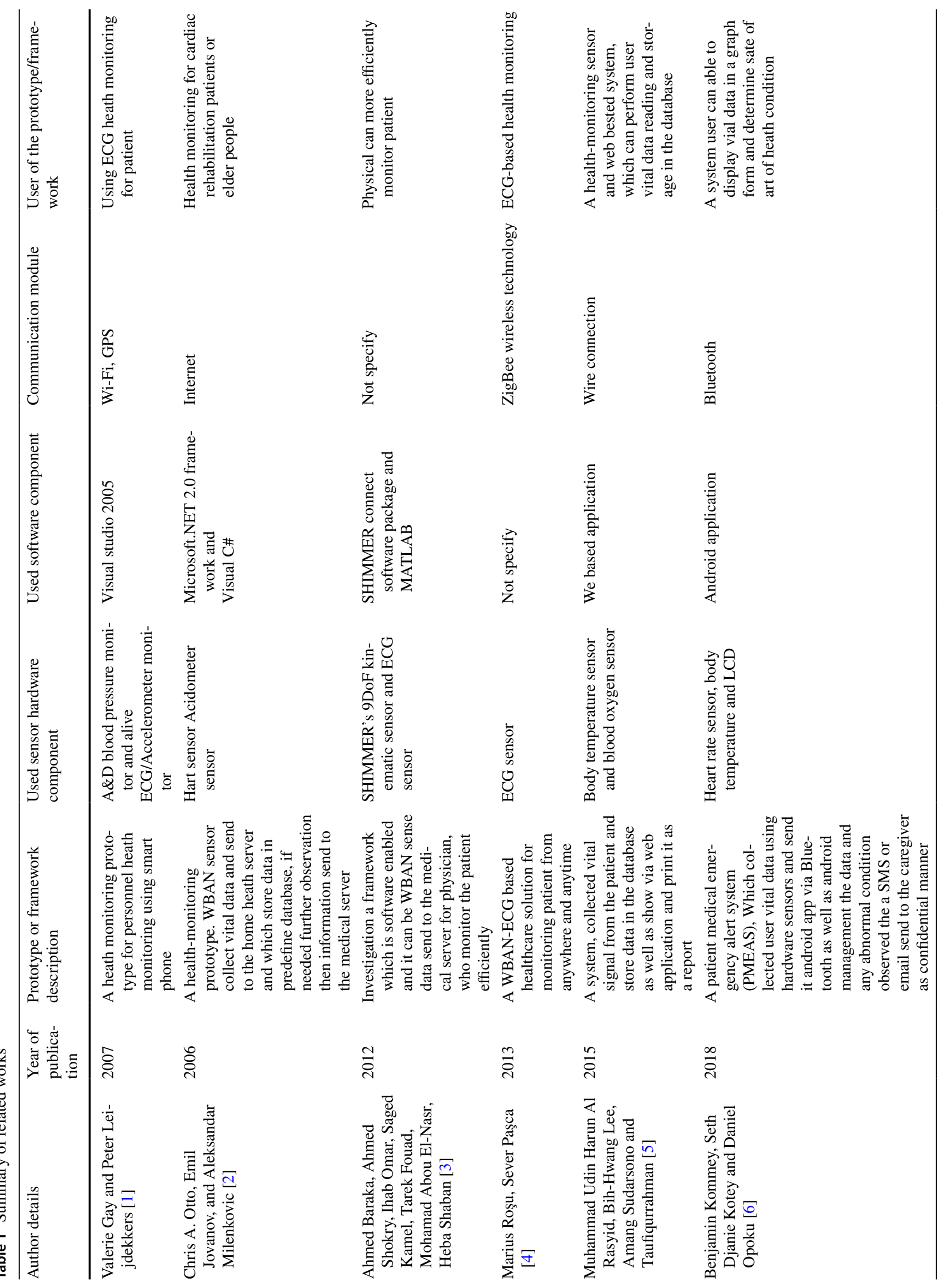




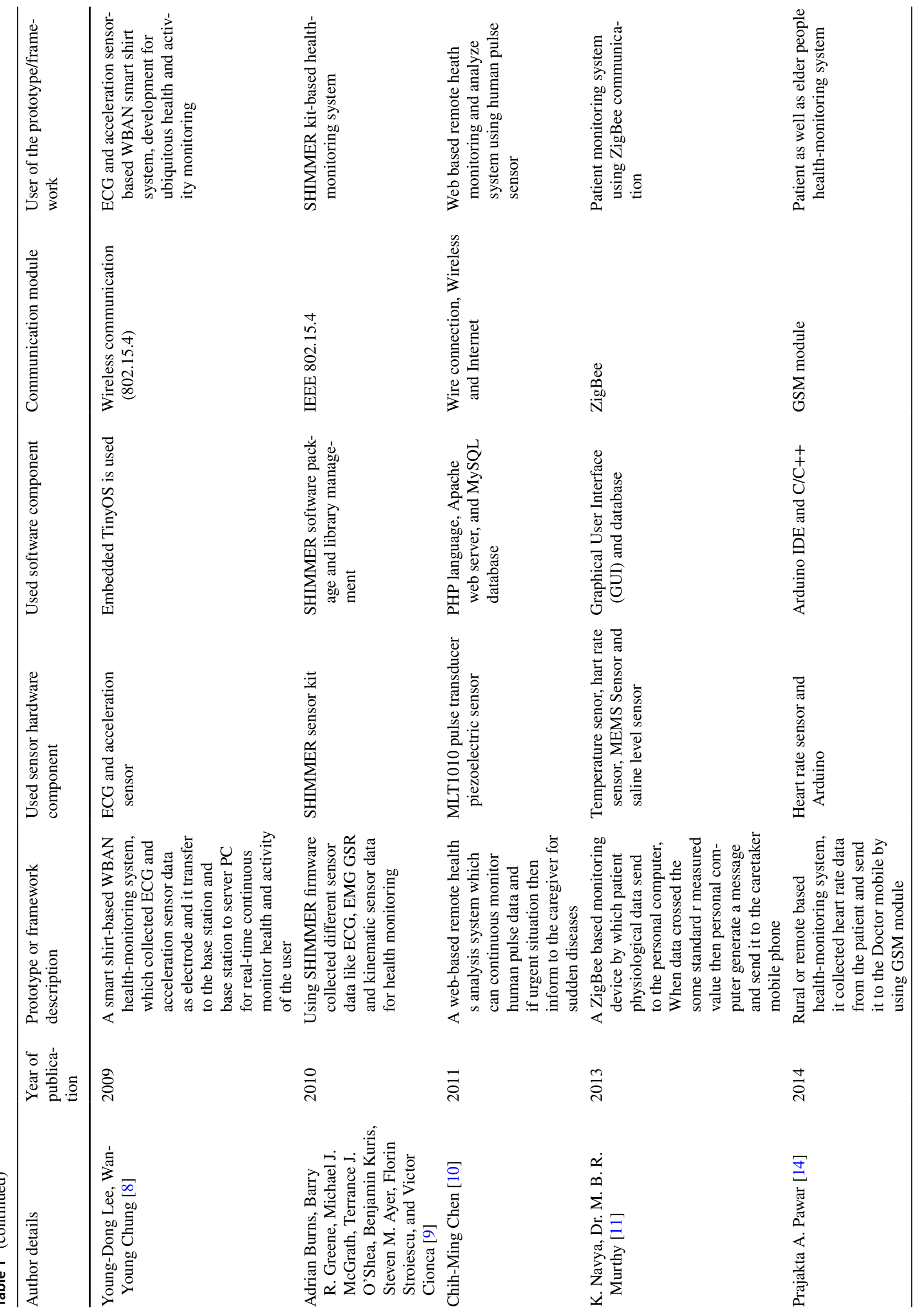




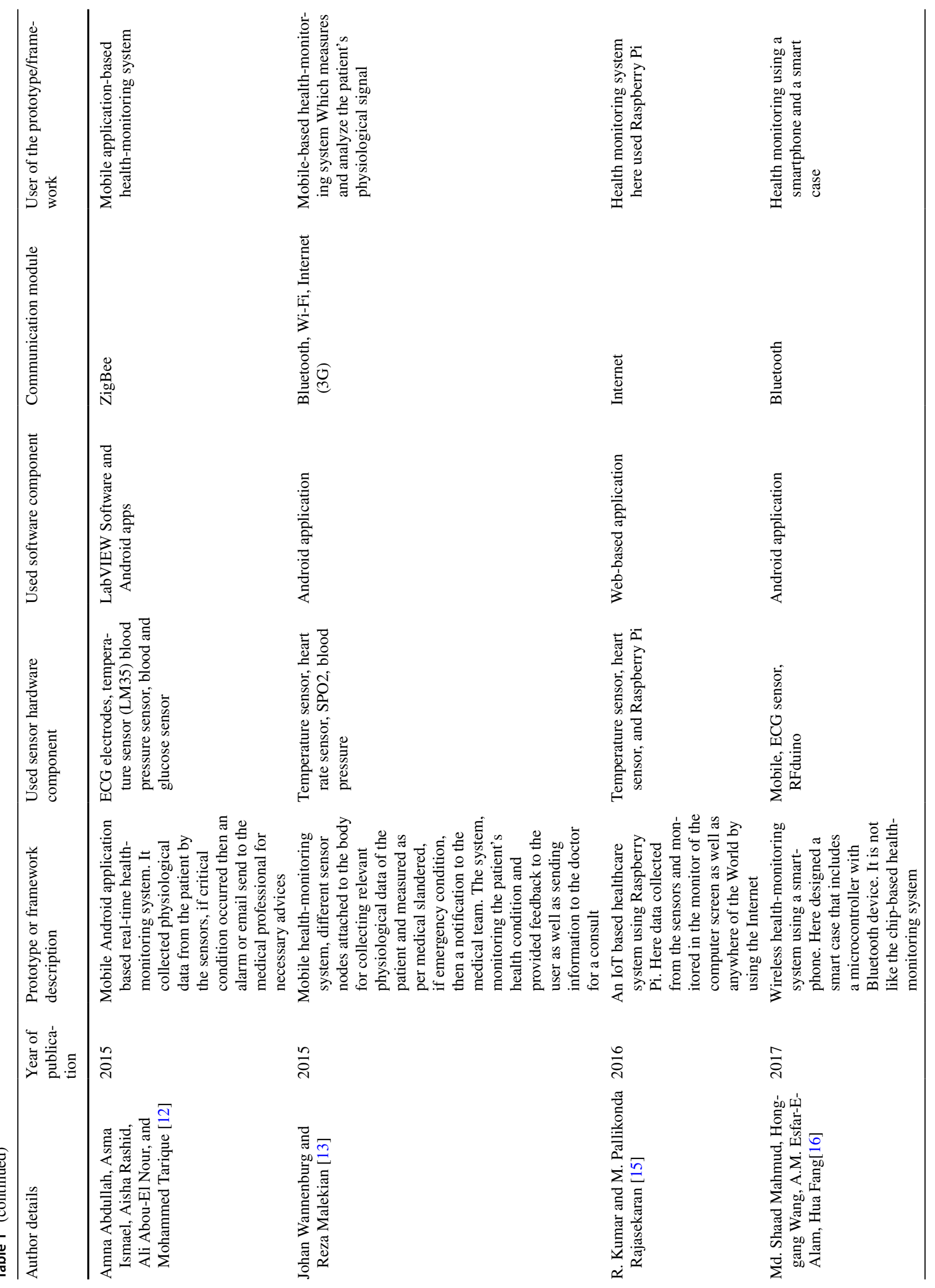




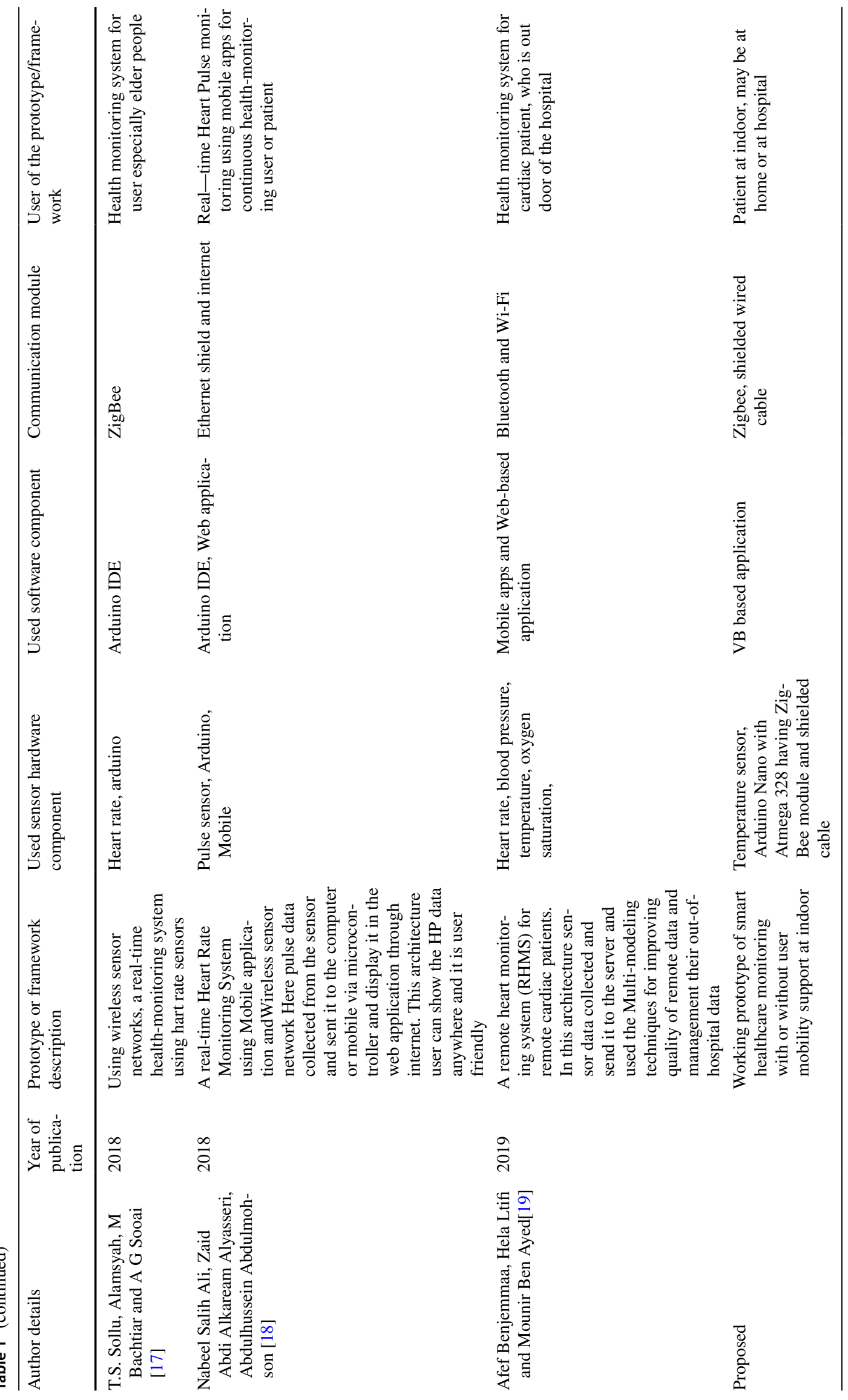


Shaad Mahmud et al. [16] proposed a prototype of healthcare to study patient vital data. Authors focused on real-time Electrocardiogram and heart rate monitoring using a smartphone case. The proposed system is an embedded system. A 3D printed PDA device is also developed by the author to validate the proposed embedded system. The system can be a comparable medical-grade device.

T. S. Sollu1 et al. [17] has been proposed a system using a wireless sensor. It can be monitoring the patient heartbeat. The system uses an electrocardiogram (ECG) mounted on the patient's body, and ECD data sent to the server through the ZigBee. Author concerned with heart rate monitoring is essential for health, especially for the elder people.

Nabeel Salih Ali et al. [18] proposed a system in real-time to monitor health based wireless sensor technology. In the proposed system, they have concentrated on the heart pulse (HP) of the patient. The proposed system provides a userfriendly solution and it is not only for the specialist.

Afef Benjemmaal et al. [19] implemented and design a remote heart monitoring system for cardiac patient. The proposed system sent and analyzed the collected real-time data to take an important decision- making in the case of remote cardiac patients. Here used two important technology is used. One is a machine learning approach, and another is visual analytic for gaining instant for collected real-time data from a sensor. In the RHMS system used multi-agent modeling for improved quality, which helped remote patients to improve the management of their out-of-hospital data.

Related works that focus on real-time different sensorbased health-monitoring system and provided solutions are summarized in Tables 1 . A detailed study on papers published during 2004 to 2019 is done to find the trends of IoT based healthcare systems.

Figure 2 shows the graphical presentation based on a published paper on remote healthcare solutions using hardware sensor devices to build working prototype compared to total publication on healthcare. In 2016 and 2017 more device based works have been published in compared to 2015, 2018 and 2019.

\section{Motivation and Contribution}

Real-time health-monitoring system design is a challenging task to implement using the WBAN sensor nodes [26, 27]. Many people suffering from ailments may not receive treatment in proper time due to unavailability of local healthcare facility as moving to further distance causes time and money which may not be affordable always. Here comes the role of proposed IoT and sensor-based model for acquisition and analysis of patient vitals remotely to provide primary care to any abnormality identified [28]. Patient vitals sensed through sensors are analyzed at local server to find the health condition. If any abnormality found that can be intimated to the doctor for necessary advice and support without physical movement of the patient thus eliminating the above mentioned problems. Here lies the motivation of design and development of proposed model.

\section{Contribution}

This simple health vital monitoring with user mobility support using Zigbee module for wireless data transferis contributed as follows:

(i) Usable and low cost working prototype for human body temperature collectionusing temperature sensor

(ii) The server analyses the data continuously in real time and patient's health condition in terms of sensed vital is displayed on monitor of developed system for notice of concerned person

(iii) Why only temperature sensor used here? The reason behind is that the normal body temperature of an individual changes based upon sex, ongoing movement, nourishing, and liquid utilization, time of day, and for females during different phases of biological changes, thus can primarily indicate any abnormality.

\section{Methodology and Implementation}

The proposed system includes: (a) system design, (b) system installation and (c) coding. Figure 3 shows the different important stages of the integrated prototype.

\section{Used Hardware Components}

The different hardware components used are described below: among various physiological primary parameters to observe from the patient is body temperature. So a body temperature sensor is required for collecting temperature as a vital signal which is measured using an embedded system that is connected with the sensor and processing of the vital signal. Here the DS18B20 [26, 28] temperature sensor is used and shown in Fig. 4 [26, 28, 29]. Advanced features of used temperature sensor are 1-wire interface, 64-Bit serial stored in an On-Board ROM, not required external component. It operates using power supply $3.0 \mathrm{v}-5.5 \mathrm{v}$.

After collecting the sensor data by using temperature sensor, required to connect with interface and power supply of the system, here used Arduino with micro-controller ATmega328. Our proposed system used Arduino Nano, shown in Fig. 5 [30]. The main purpose of using Arduino Nano is that it is embedded with ATmega328. It has many advantages over Arduino Uno. ATmega328 is an 8-bit AVR Microcontroller manufactured by Microchip, follows RISC 


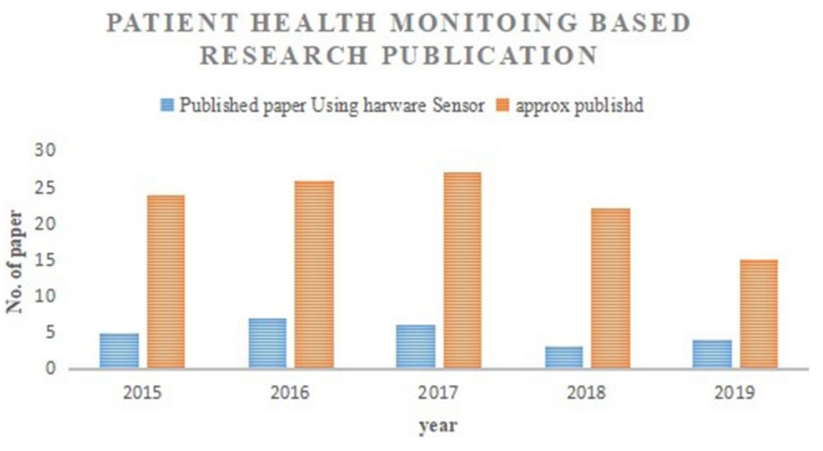

Fig. 2 Comparison of publication of hardware sensor and IoT based remote healthcare and total healthcare solutions

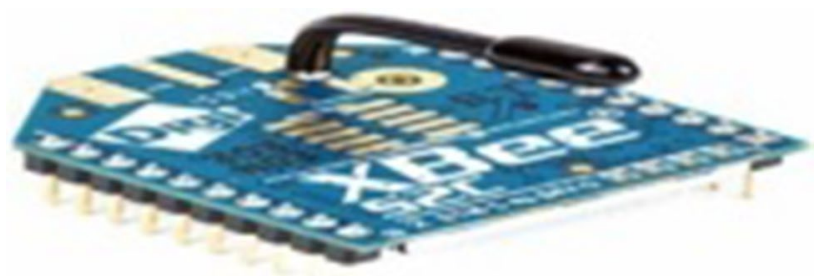

Fig. 6 ZigBee communication module
Fig. 3 Different stage of the proposed prototype

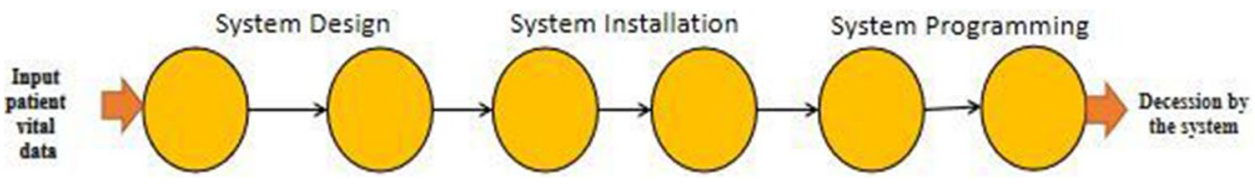

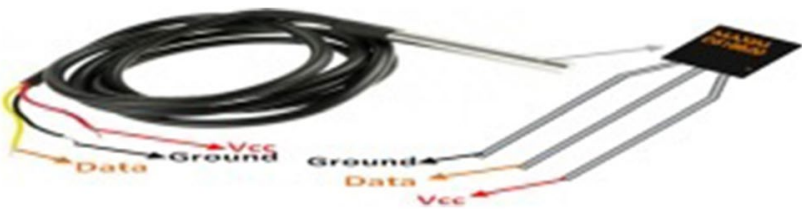

Fig. 4 DS18B20 temperature Sensor

architecture, and it has a flash type program memory of $32 \mathrm{~KB}$. ATmega328 has 28 pins. ATmega328 has $1 \mathrm{~KB}$ Electrically Erasable Programmable Read-Only Memory (EEPROM) and 2 KB SRAM memory.

The embedded sensor and microcontroller are used to collect data from the patient's body and need to connect to the CCU or computer. Generally, in the market, there are different types of communication modules available like Bluetooth, Wi-Fi, ZigBee, and USB shielded cable, and so on. In particular, an application like in our proposed system can be decided by examining several characteristics like power consumption, data rate and range. Based on the above characteristics, ZigBee is used for wireless communication shown in Fig. 6 [25] and for wired connection USB shielded cable for when patients in the range of CCU or computer. In healthcare applications, ZigBee is more suitable over other wireless communication. ZigBee has the following features like power consumption is very low, the range of ZigBee is very large ( $300 \mathrm{ft}-40$ miles), the data rate in $\mathrm{ZigBee}$ ( 250 $\mathrm{Kbit} / \mathrm{s}$ ) is low as well as the cost is low.

\section{Used Software Components}

In the proposed system different hardware is described above, now needs to interface hardware to the software system and establish a reliable communication system for healthcare. Different software and APIs are used in the proposed system.
Fig. 5 Arduino Nano with pin configuration

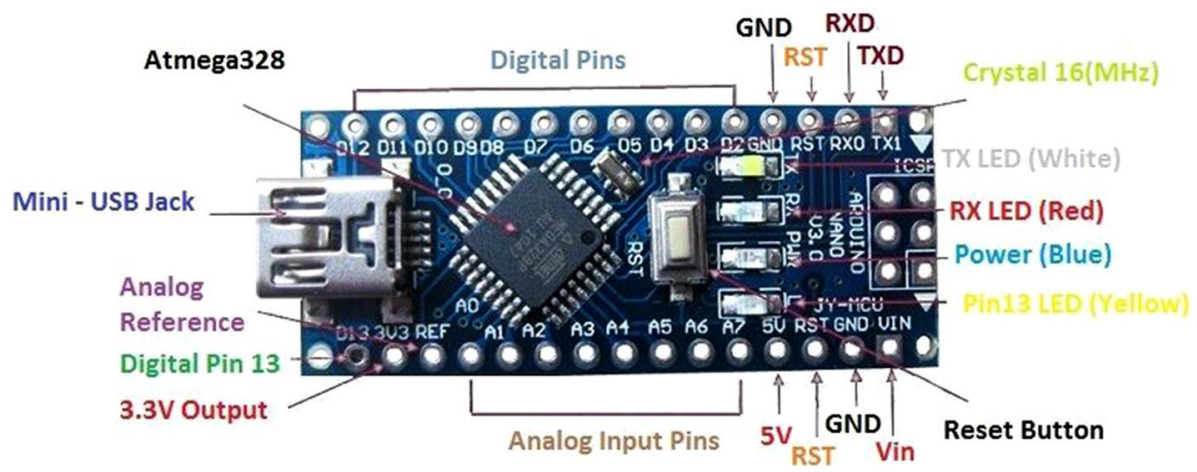


Fig. 7 Using ZigBee communication

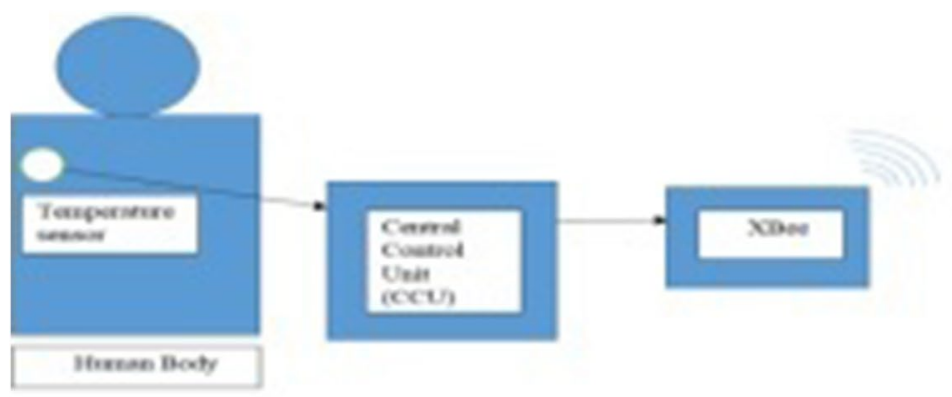

Fig. 8 Using Shielded USB cable

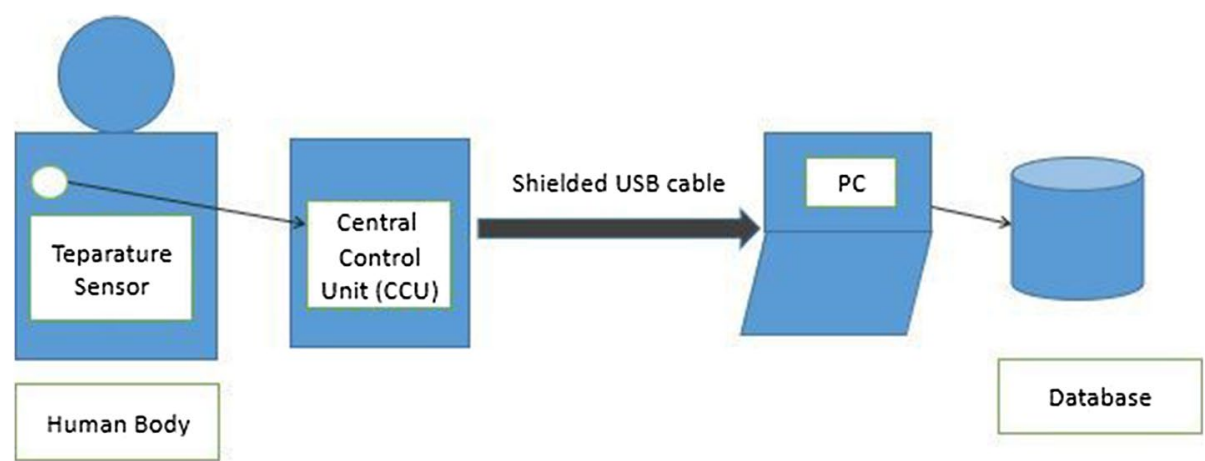

\section{Arduino IDE}

Arduino IDE [24, 32], i.e., Arduino Integrated Development Environment. It connects to Arduino and hardware for uploading programs and communicating with them. Programs are written in Arduino IDE editor. It is an open source and easy programming environment for Arduino modules.

\section{Microsoft Visual Basic 6}

Programs created with Visual Basic run on Windows, on the Web, within Office applications, or on mobile devices. Using Visual Studio programs are created compatible in all these platforms thus preferred by all educationists and budding researchers. Visual Studio.NET provides development tools to create programs based on the.NET framework, such as ASP.NET applications, which are often deployed on the Web.

\section{WAMP Server}

WAMP Server [33, 34] allows us to develop dynamic applications based on web with MySQL, PHP and Apache 2 [35].

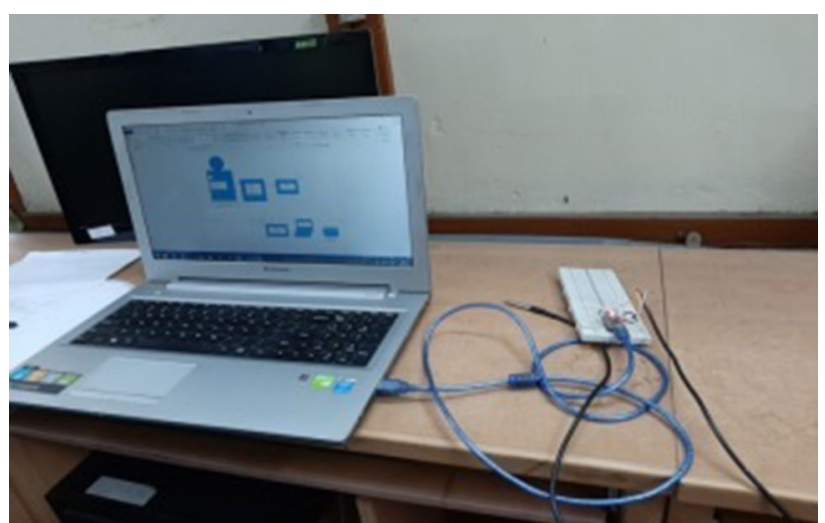

Fig. 9 Wired connection of the implemented system

WAMP Server automatically installs everything you need to intuitively develop Web applications. There are many useful feature line MySQL services for Database management, switch online/ offline to give access to everyone, or only localhost and manage servers. 


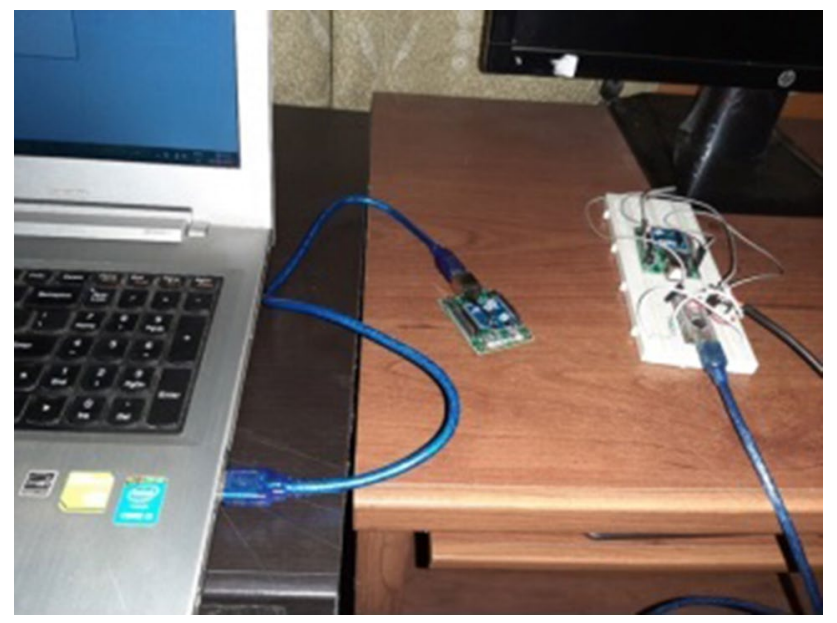

Fig. 10 Wireless connection of the implemented system

\section{XCTU}

XBee Configuration and Test Utility (XCTU) [20] is a program using which users can interact with devices enabled with digital radio frequency $(\mathrm{RF})$ through a graphical interface. Built-in tools of this application make it easy to set up, configure, and test digital RF devices.

\section{Implementation of Working Prototype}

Now all the softwares required for the proposed system are installed and the hardware system is arranged properly. In this proposed system, two types of communication are used: one is wired communication for the patient who is in a static position using Shielded USB, and another is wireless communication for the patient who is mobile using ZigBee communication. Here body temperature sensor is used to read body vital to analyze and find the health fever condition according to predefined medical science information. Block diagram of both the systems is shown in Figs. 7 and 8 .

In wired connection, body temperature sensor is connected to the Central Control Unit, here micro-controller Arduino with breadboard proper connections. Then Arduino connected to the PC and real-time data transfer to PC. In case of wireless connection, CCU or Arduino connected to the transmitter of the ZigBee in the bard board with proper connection and receiver of the ZigBee in connected to the PC. Both connections are shown in Figs. 9 and 10.

Now, all the software's need to be installed to create a real-time data collection system. Per user a unique-id is created along with several attributes e.g. age, gender, address, contact, email etc. All these details are stored in the database which include attribute of the $\mathrm{PC}$ which is required for the proposed system, create a real-time data connection system where user can create own-id which include attribute and back end database shown in Fig. 11 which stores data for future purpose.

Now, the proposed system is ready for monitoring patient using body temperature. The normal body temperature of an individual change relying upon sex, ongoing movement, nourishment, and liquid utilization, time of day, and for females during the phase of the menstrual cycle. Typical

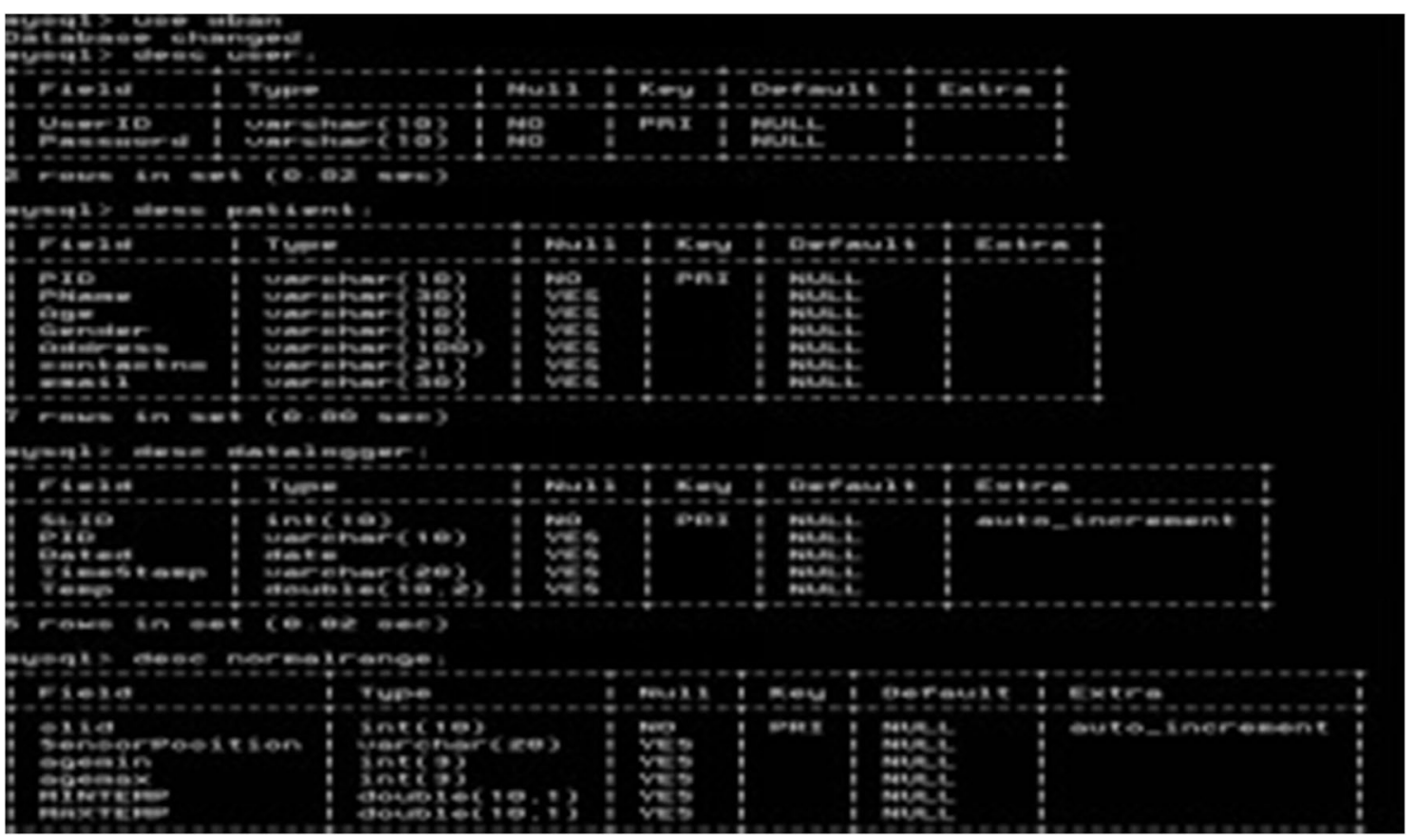

Fig. 11 Back-end database of the system 


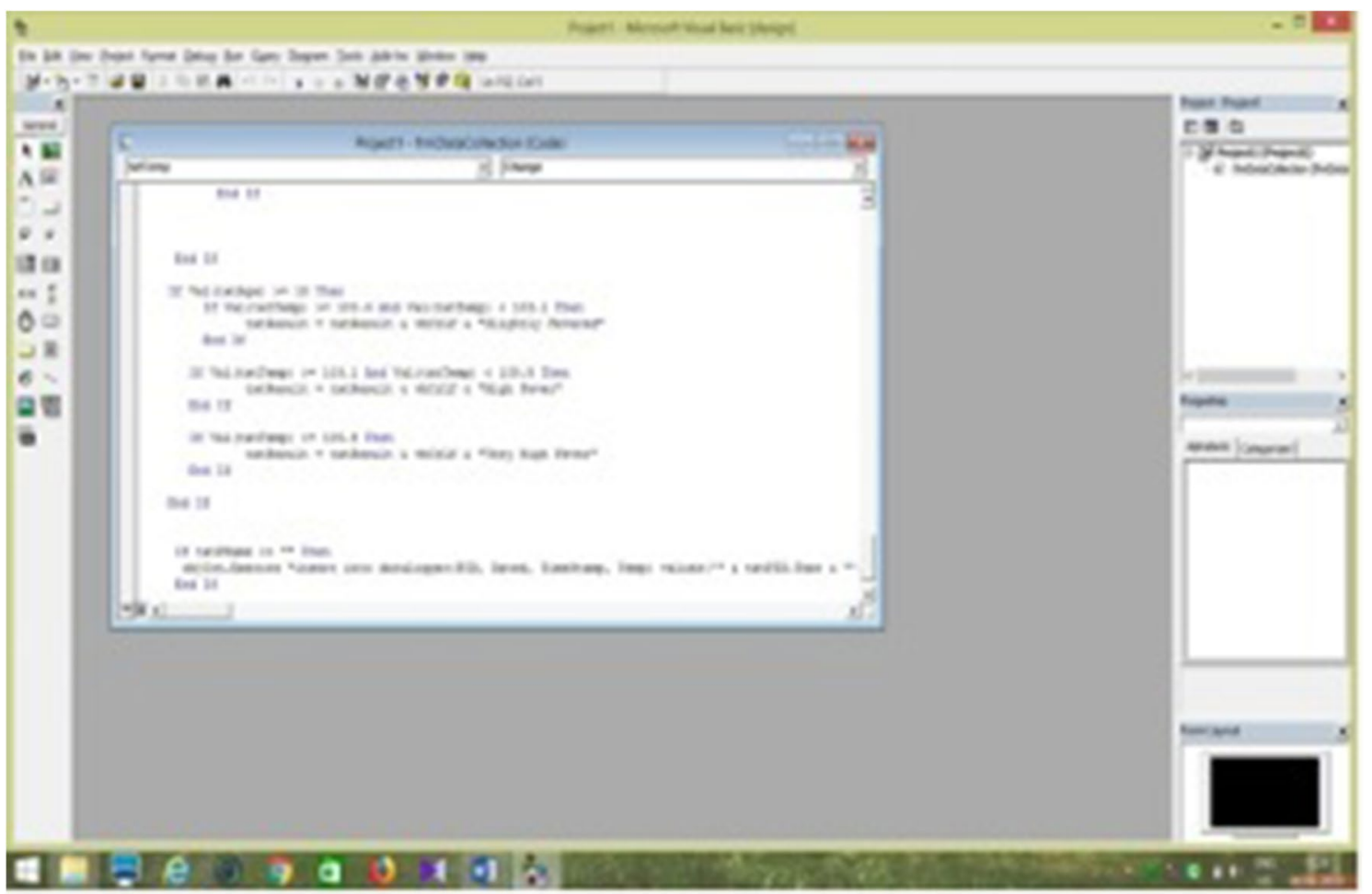

Fig. 12 Medical science data in VB program

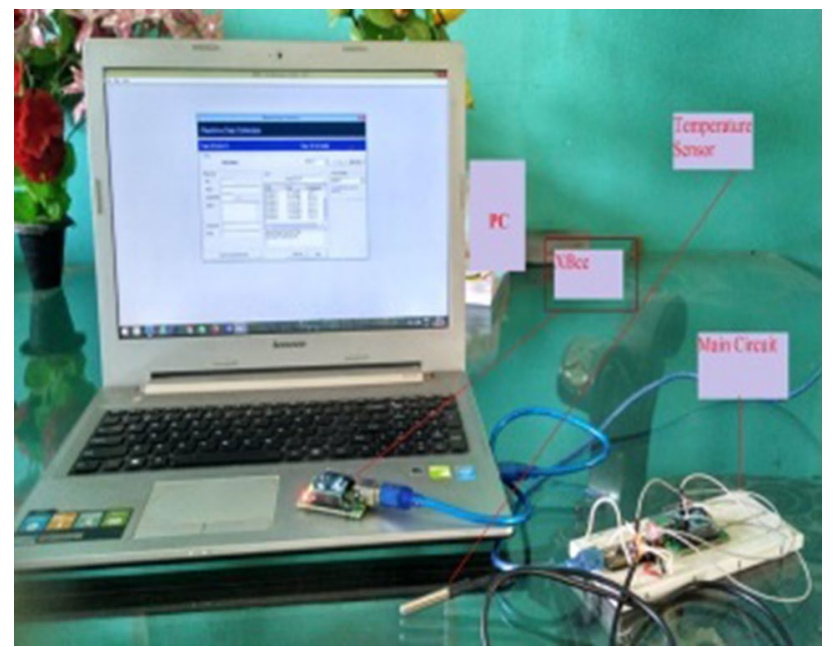

Fig. 13 Prototype model of health vital collection and analysis

body temperature can extend from $97.8^{\circ} \mathrm{F}\left(36.5^{\circ} \mathrm{C}\right)$ to $99^{\circ} \mathrm{F}$ $\left(37.2^{\circ} \mathrm{C}\right)$ for a sound grown-up. An individual's body temperature [21-25] can be taken in any of the accompanying ways as given below:

\section{Orally and Rectally}

Oral and rectal temperatures [21] are measured by the doctors using great glass thermometer or computerized thermometers. In general, rectallyacquired temperature is in the range of $0.5^{\circ} \mathrm{F}$ to $0.7^{\circ} \mathrm{F}$.

\section{Armpit (Axillary)}

Armpit temperature [21] can be measured using a glass or advanced thermometer. In general be $0.3-0.4{ }^{\circ} \mathrm{F}$ lower than those temperatures taken by mouth.

\section{By Ear and by Skin}

A kind of special thermometer may be used for the purpose of collecting ear and skin temperature [21].

\section{Internally}

This method [20]is used for people critically ill and in ICU by placing measuring probes in the esophagus, heart, or bladder. Body temperature may be abnormal due to fever (high temperature) or hypothermia (low temperature). According to the American Academy of Family Physicians, temperature $1^{\circ}$ more than normal temperature of $98.6^{\circ} \mathrm{F}$ is 


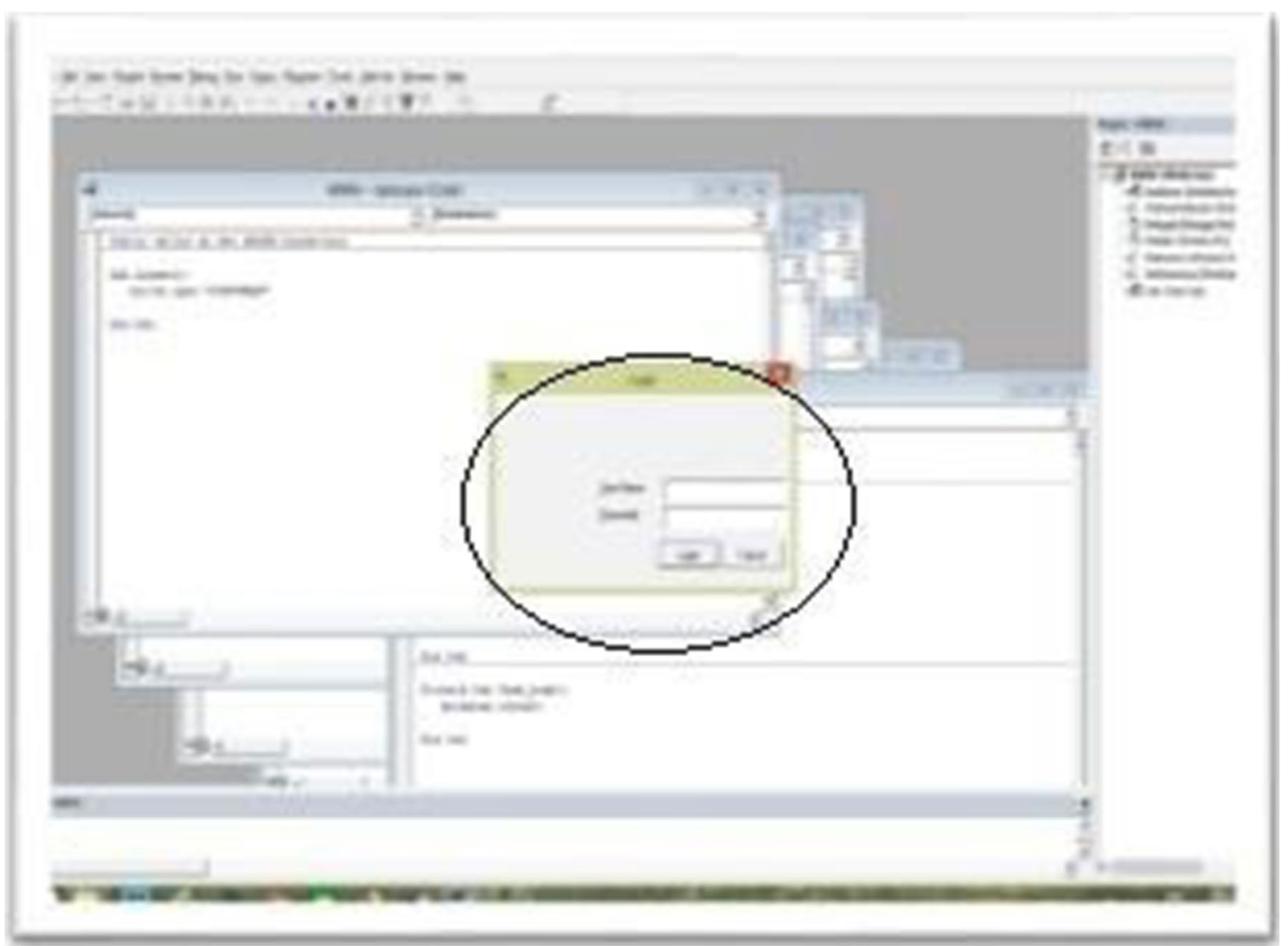

Fig. 14 Login page

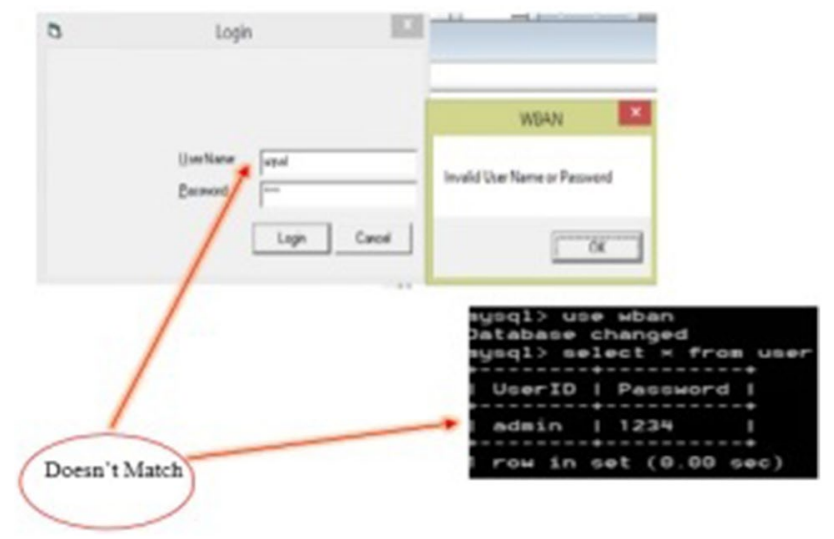

Fig. 15 login credentials not matched with existing database 


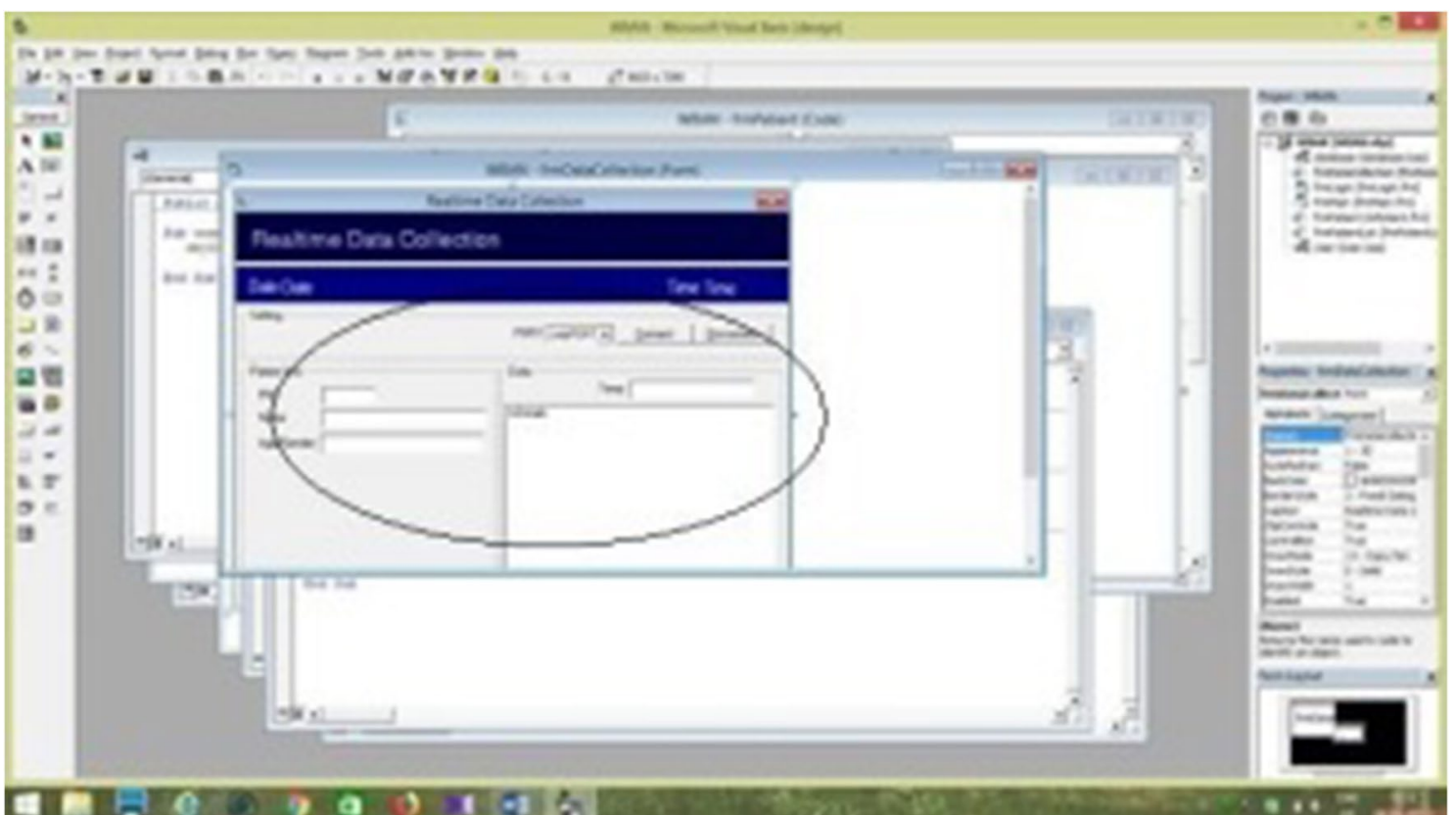

Fig. 16 Accessibility by the user to collect real-time data

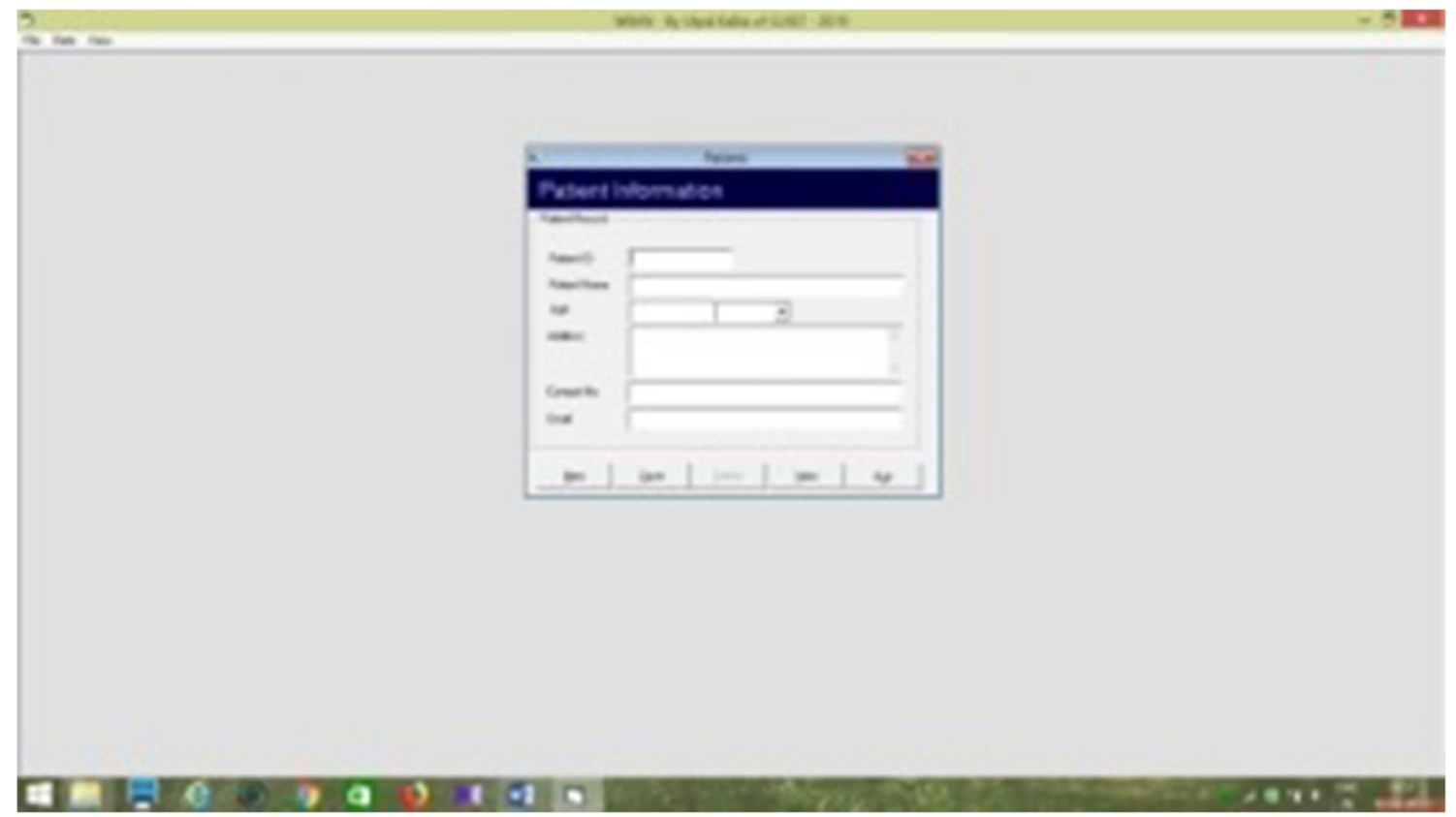

Fig. 17 Administrator adds new patient 


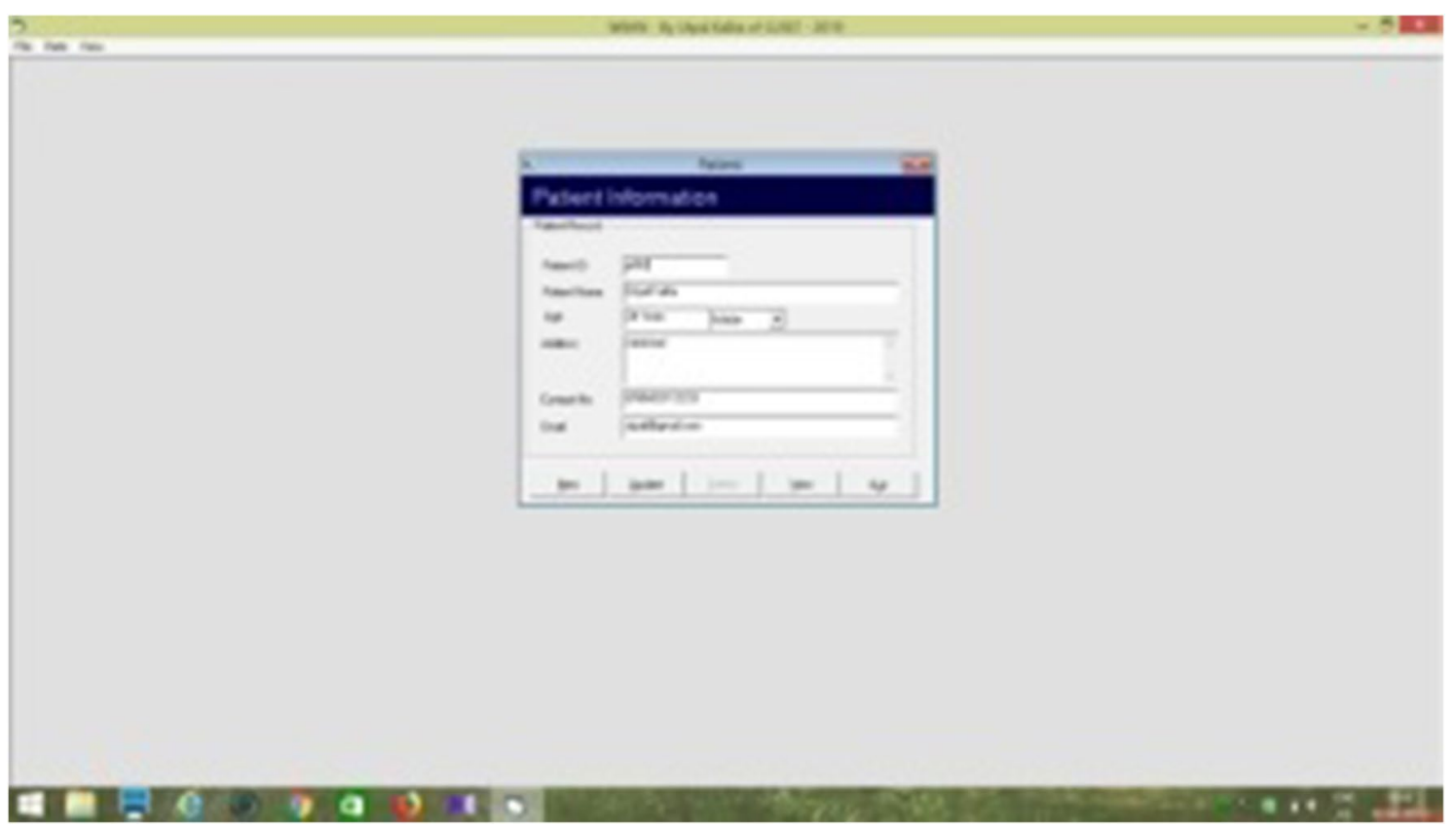

Fig. 18 Administrator updates patient information

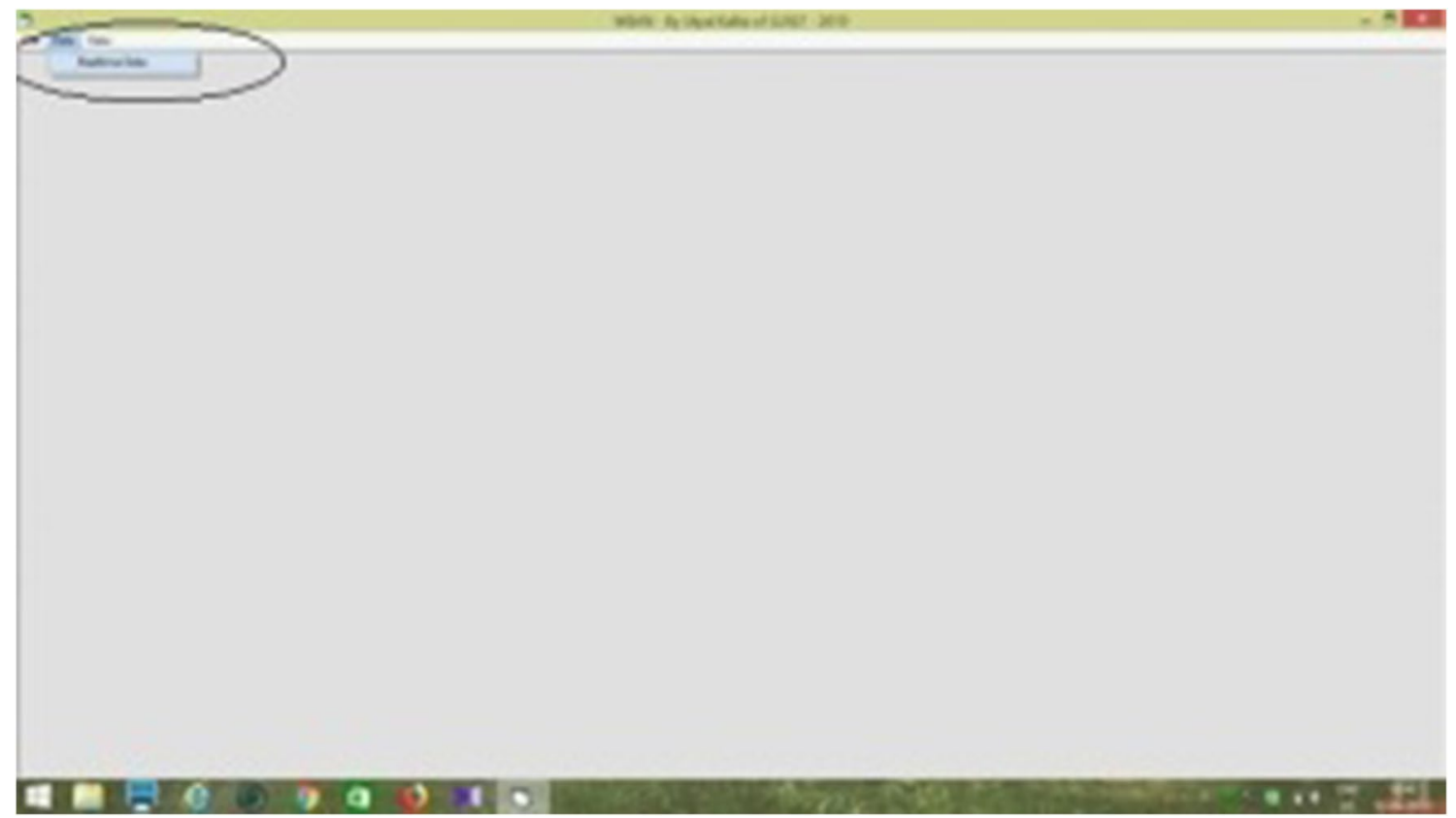

Fig. 19 Administrator can check previous data 


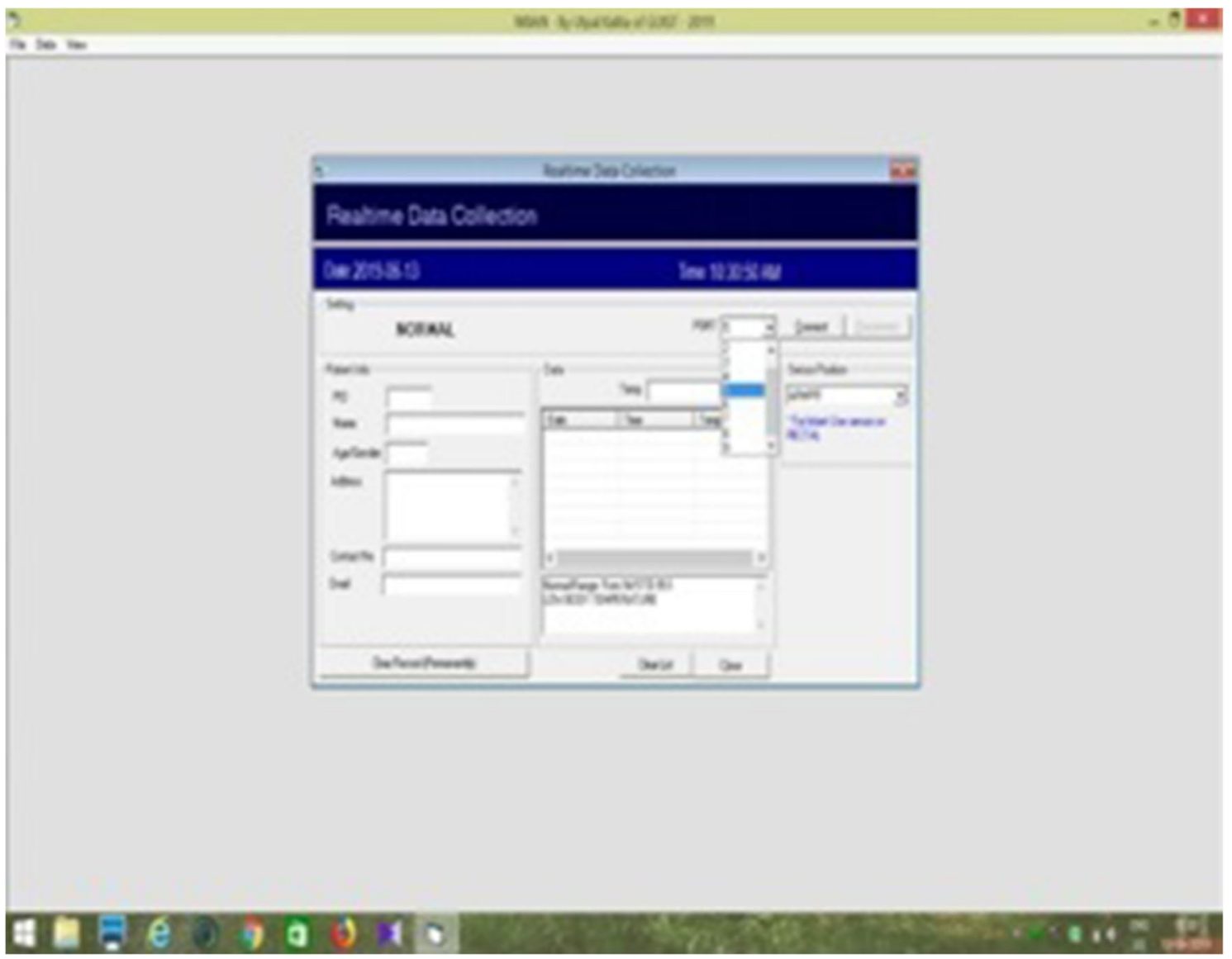

Fig. 20 Create id and password of sensor hardware port of CCU

Table 2 Body temperature of normal range for adult and child according to the medical science [20-25]

\begin{tabular}{|c|c|c|c|c|}
\hline Type of reading & $0-2$ years & $3-10$ years & $11-65$ years & Over 65 years \\
\hline Oral & $95.9-99.5^{\circ} \mathrm{F}\left(35.5-37.5^{\circ} \mathrm{C}\right)$ & $95.9-99.5^{\circ} \mathrm{F}\left(35.5-37.5^{\circ} \mathrm{C}\right)$ & $97.6-99.6^{\circ} \mathrm{F}\left(36.4-37.6^{\circ} \mathrm{C}\right)$ & $96.4-98.5^{\circ} \mathrm{F}\left(35.8-36.9^{\circ} \mathrm{C}\right)$ \\
\hline Rectal & $97.9-100.4^{\circ} \mathrm{F}\left(36.6-38^{\circ} \mathrm{C}\right)$ & $97.9-100.4^{\circ} \mathrm{F}\left(36.6-38^{\circ} \mathrm{C}\right)$ & $98.6-100.6^{\circ} \mathrm{F}\left(37.0-38.1^{\circ} \mathrm{C}\right)$ & $97.1-99.2^{\circ} \mathrm{F}\left(36.2-37.3^{\circ} \mathrm{C}\right)$ \\
\hline Armpit & $94.5-99.1^{\circ} \mathrm{F}\left(34.7-37.3^{\circ} \mathrm{C}\right)$ & $96.6-98.0^{\circ} \mathrm{F}\left(35.9-36.7^{\circ} \mathrm{C}\right)$ & $95.3-98.4^{\circ} \mathrm{F}\left(35.2-36.9^{\circ} \mathrm{C}\right)$ & $96.0-97.4^{\circ} \mathrm{F}\left(35.6-36.3^{\circ} \mathrm{C}\right)$ \\
\hline Ear & $97.5-100.4^{\circ} \mathrm{F}\left(36.4-38^{\circ} \mathrm{C}\right)$ & $97.0-100.0^{\circ} \mathrm{F}\left(36.1-37.8^{\circ} \mathrm{C}\right)$ & $96.6-99.7^{\circ} \mathrm{F}\left(35.9-37.6^{\circ} \mathrm{C}\right)$ & $96.4-99.5^{\circ} \mathrm{F}\left(35.8-37.5^{\circ} \mathrm{C}\right)$ \\
\hline
\end{tabular}

considered as fever, and hypothermia is defined as a drop in body temperature below $95^{\circ} \mathrm{F}$.

In the above system used a DS18B20 temperature sensor for collecting patient body temperature instead of thermometer and set a LAB environment in our IoT lab. Although, this senor is used for collecting body temperature from the above body position. Temperature is collected as analog signal and send it to the laptop which acts as local server using micro-controller Arduino. In PC VB is used as an interfacing software which displays and stores data in specific format. Collected data that are stored in the database. Here using VB programming, acquired data is analyzed w.r.t. medical definition as given in Table 2, Fig. 12. Patient's health temperature accordingly and corresponding health condition is displayed.

\section{Experimental Results}

The result of this system can be visualized with the help of the graphical user interface of software and hardware modules. The detail of the output is illustrated step by step as follows. The system setup is shown in Fig. 13.

At first a login interface appears just like as given in run the program, once if program is executed, then a login interface is appeared just like as given Fig. 14. To start using the 


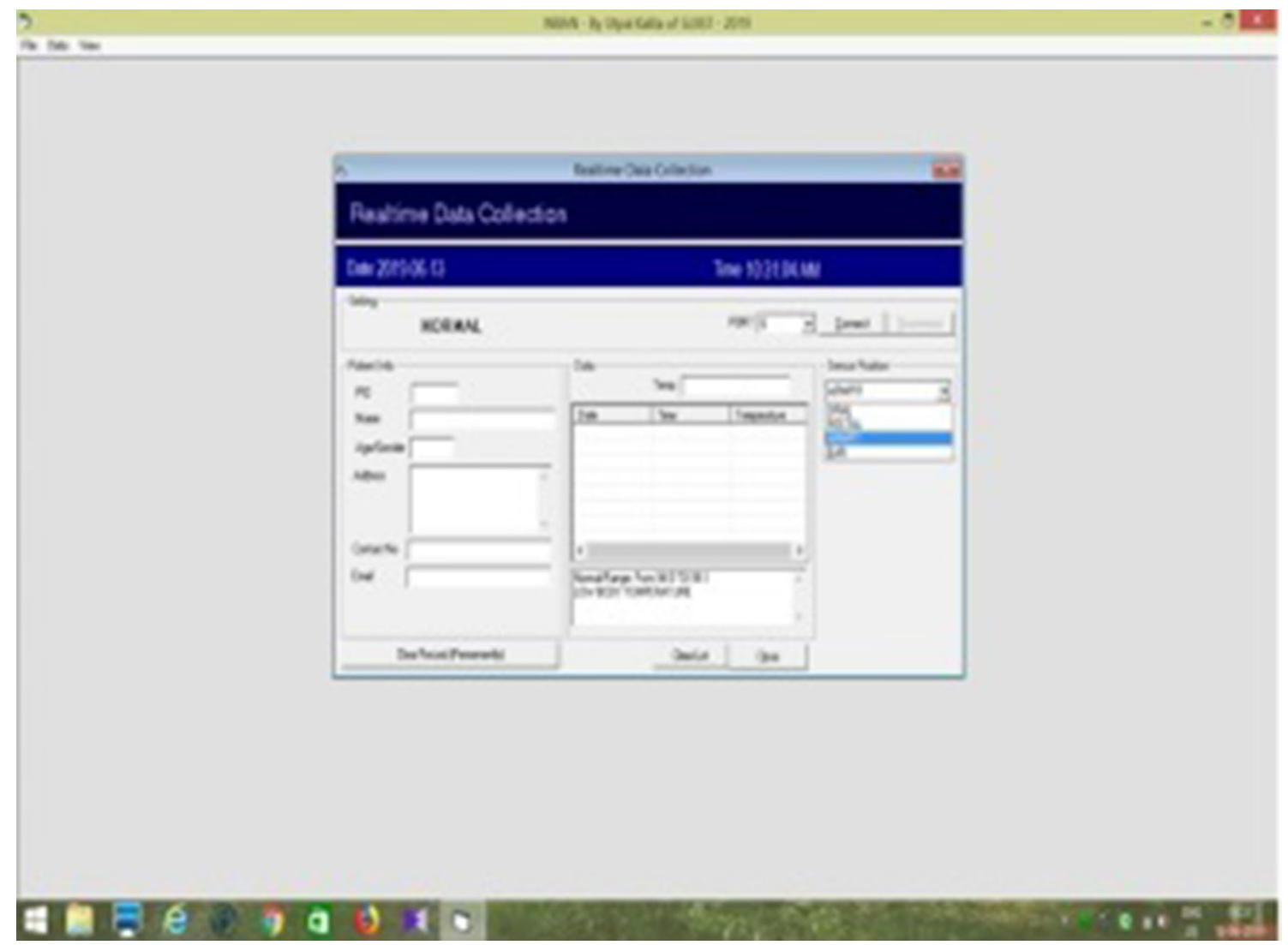

Fig. 21 Sensor data collection from different body parts

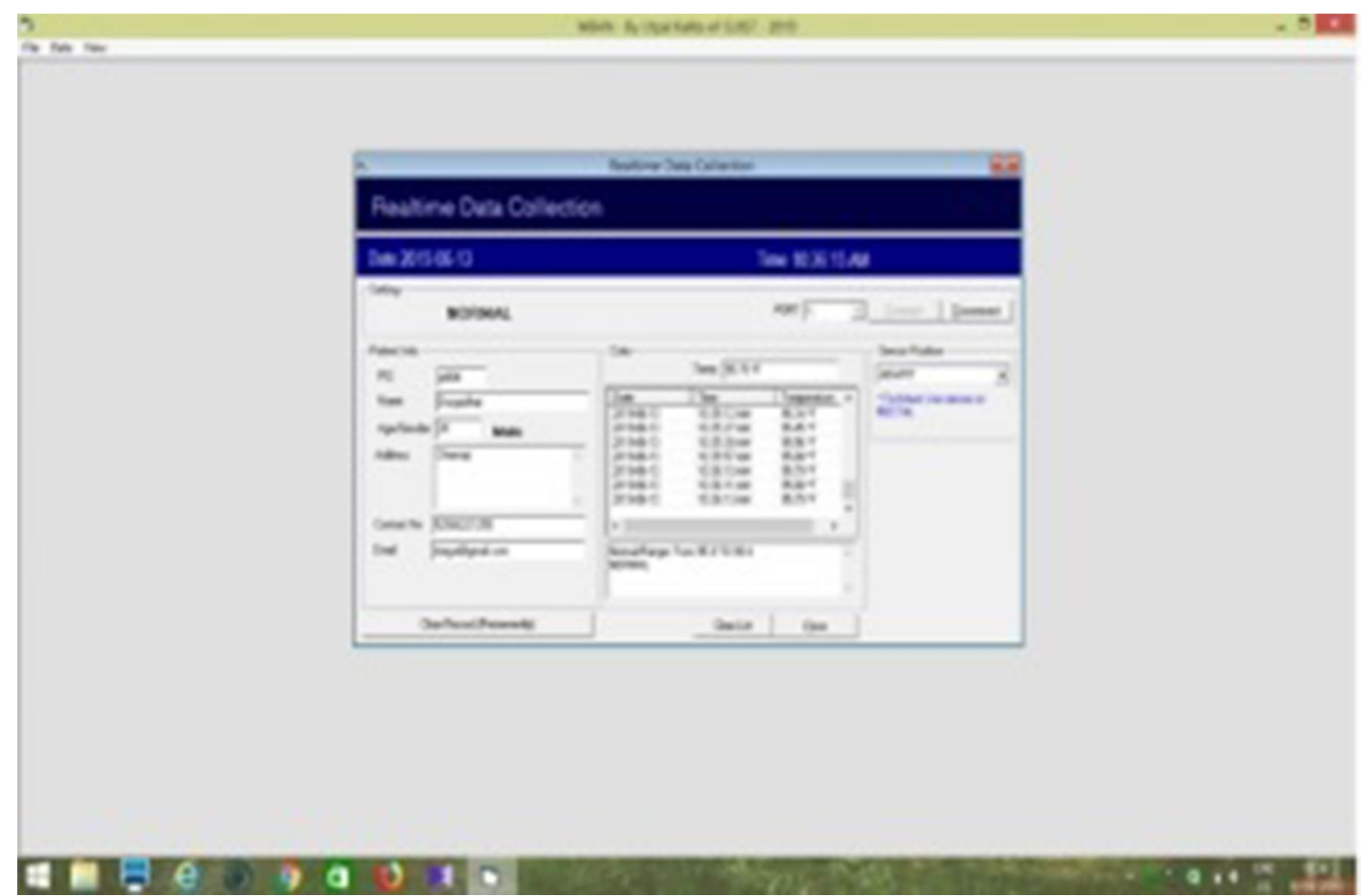

Fig. 22 System collects real-time data 


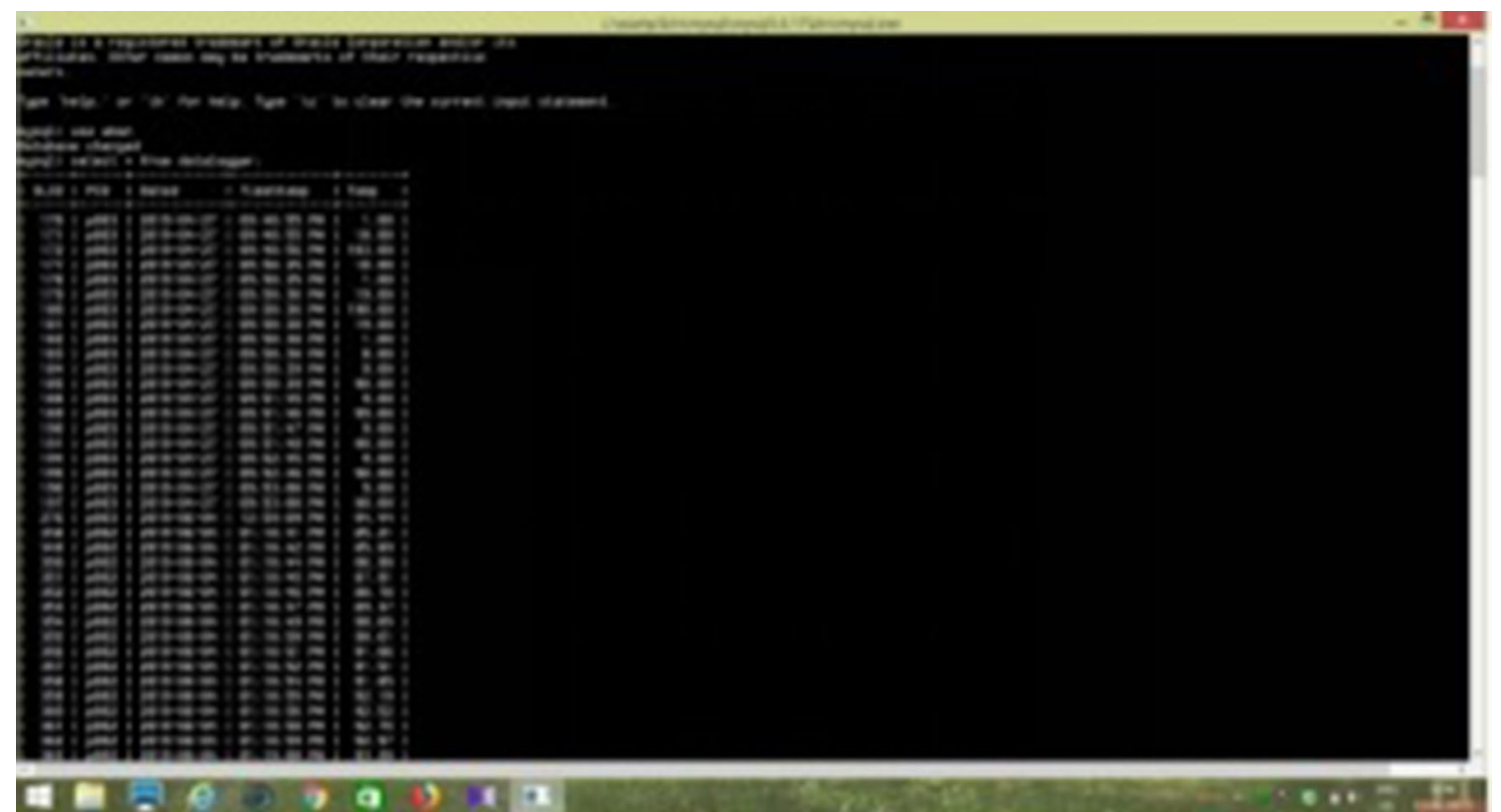

Fig. 23 Display of real-time data in the database

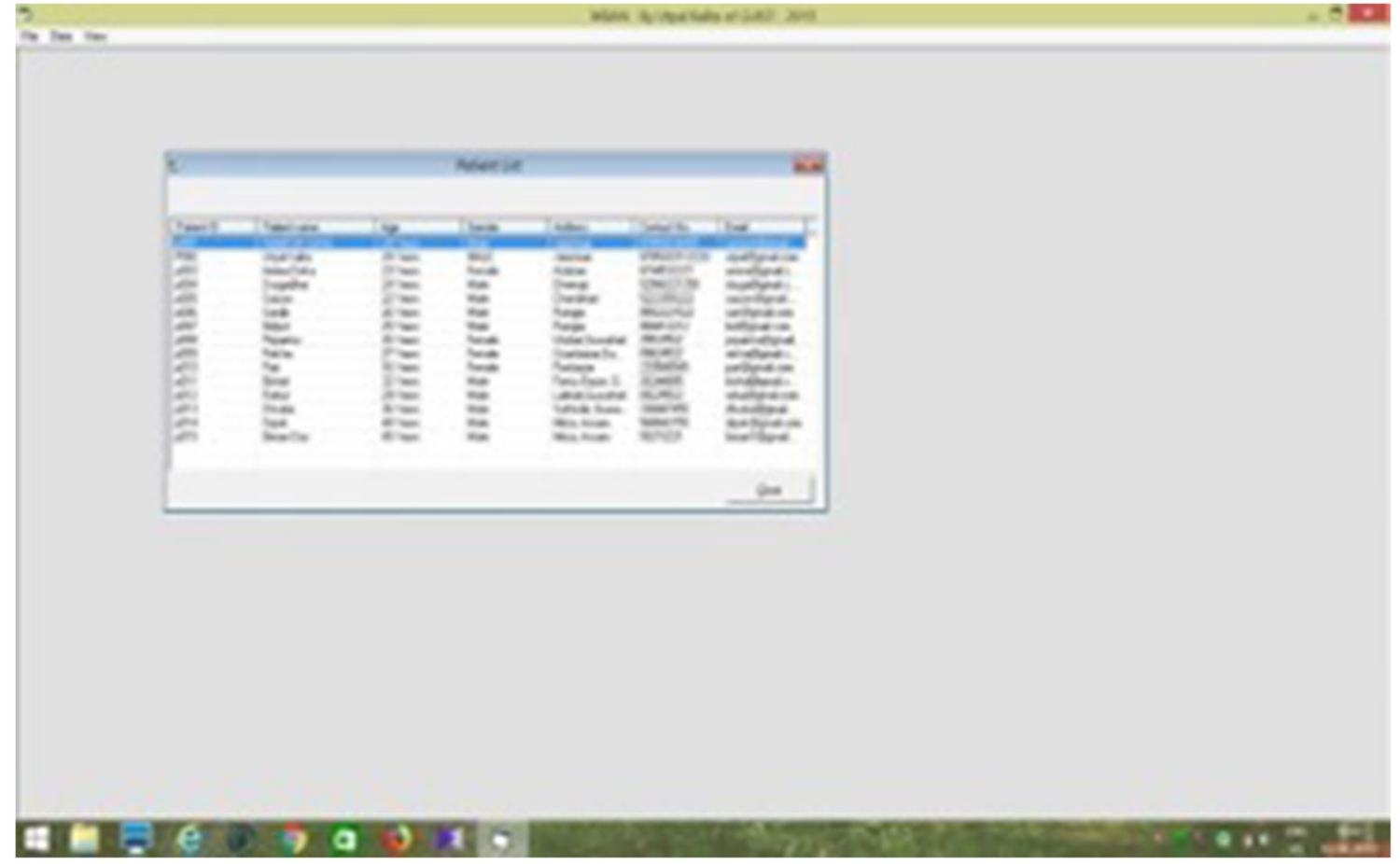

Fig. 24 Display patient list in the database 


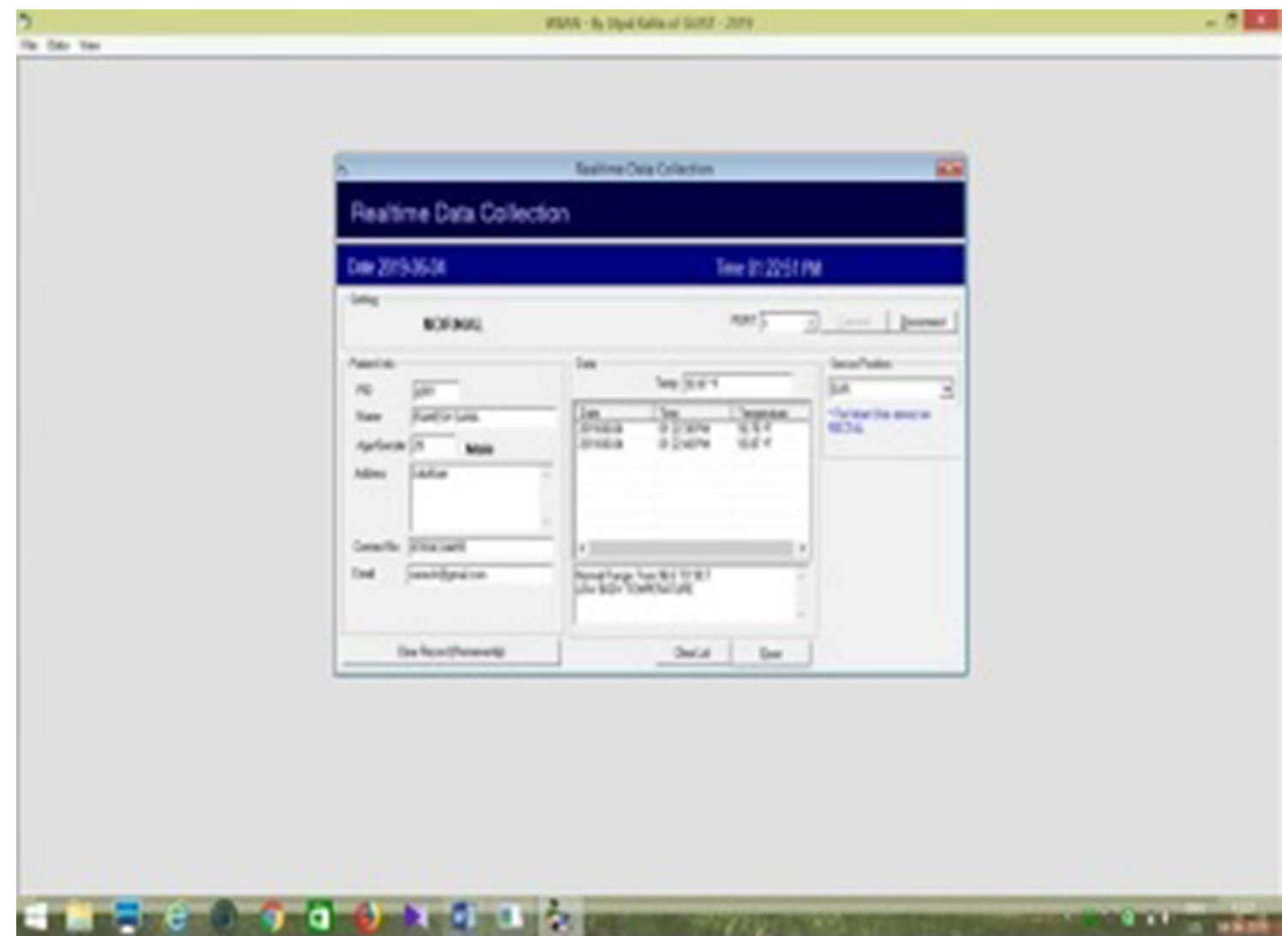

Fig. 25 Display condition of the patient

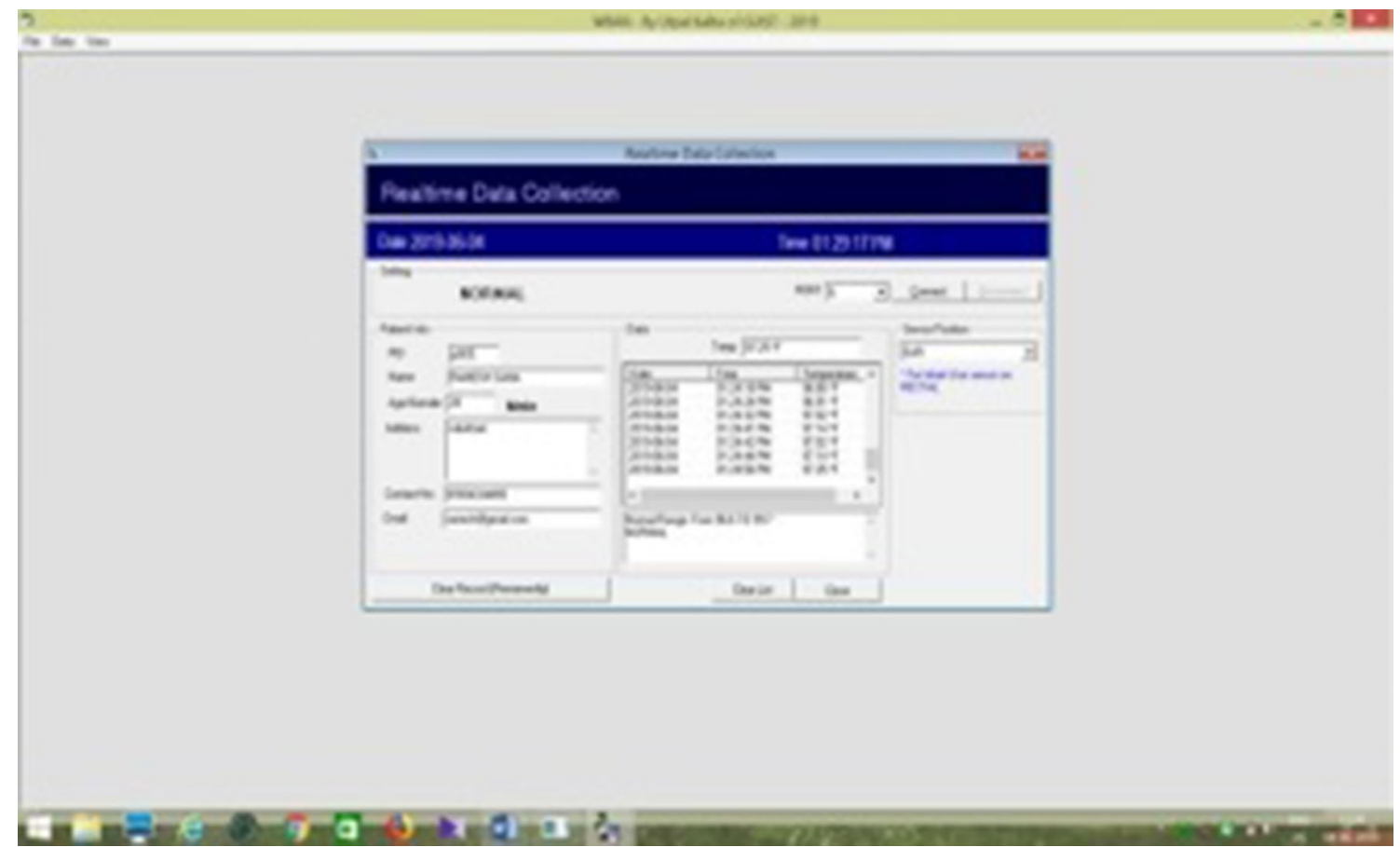

Fig. 26 Display normal condition of the patient 
system, authentication in terms of login credentials is done for both administrator and patient.

If authentication fails, no one can access the system as shown in Fig. 15.

If the username and password given by the admin matches with the database, then the admin will get the accessibility of the home page where the admin can access all the details of Patient, Patient list and also can monitor the real-time data of the Patient shown in Fig. 16.

Administrator can add new patients as shown in Fig. 17 as well as update patient table as shown in Fig. 18.

If administrator wants to check previous data it is possible in this system shown in Fig. 19.

Now new patient first create the patient login Id and password and select the hardware port in the system which is shown in Fig. 20 and position of temperature sensor of the human body like oral, rectal, armpit, ear as given in Fig. 21. This position is armpit here for collecting body temperature of the patient.

Now the administrator enter the patient id, system starts collecting real-time patient data and display. Figure 22 illustrated that currently body vital of patient id 4 is being collected and his body temperature is normal.

If any data to be retrieved, patient id has to be given and corresponding temperature with data and time will be displayed as given in Fig. 23, as well as shows the patient list of the database shown in Fig. 24.

Now, give an example of our system that how take the real-time patient data and monitoring in LAB environment. First take Ramesh Saha as a patient or user of the system. Create database and added different attribute of the patient like PID, Name, Age or Gender, address Contact Details and email-id is p001, Ramesh Saha, 28, Jalukbari, 8,765,334,455 and ramesh@gmail.com respectively. Now select the PORT here it is 6 and sensor position of the user here is EAR as being shown in Fig. 25. After sensor node is connected with the selected position i.e. EAR of the user or patient, then in data box, upper portion shows the data in the format of (date, time and temperature) which gets stored in the database automatically. Below part shows the condition of the patient as per medical science. Here in Fig. 26 is LOW BODY TEMPERATURE because collected temperature is below normal temperature i.e. 93.87 degree Fahrenheit.

Now, if body temperature is in normal range, it shows NORMAL, if more than normal range that condition of patient is also displayed. Accordingly these findings can be sent to doctor to get proper advice in time.

\section{Conclusion}

In our experimental work we are focusing on building a working prototype of a WBAN in which using a temperature sensorDS18B20, connected with the computing device, collects and transmits signals using wired and wireless communication. Here shielded USB cable and ZigBee module are used for data transfer. The outcome of the system is satisfactory after comparing the temperature obtained from a conventional medical thermometer. It is working properly the way we have designed for collecting body temperature, transmitting over wireless communication and analyzed data after receiving. Body temperature indicates symptoms of other physical abnormalities hence needs to be monitored, specifically for elderly and diseased people with freedom of movement due to daily cores at indoor. The working prototype can be extended including other sensors e.g. pulse rate sensor, heart rate sensor, Spo2, Nasal airflow sensor etc. to build a prototype for COVID 19 patient monitoring at home.

Acknowledgements This work has been partially supported with the grant received in research project with sanction no. CRS ID:-15758863831from MHRD, Govt. of India under TEQIP III in Collaborative Research Scheme (CRS), AICTE.

\section{Compliance with Ethical Standards}

Conflict of interest None.

\section{References}

1. Gay V, Leijdekkers P. A health monitoring system using smart phones and wearable sensors. Int J ARM. 2007;8(2):29-35.

2. Otto CA, Jovanov E, Milenkovic A. A WBAN-based system for health monitoring at home. In: 2006 3rd IEEE/EMBS International Summer School on Medical Devices and Biosensors. IEEE, pp 20-23 2006.

3. Baraka A, Shokry A, Omar I, Kamel S, Fouad T, El-Nasr MA, Shaban H. A WBAN for human movement kinematics and ECG measurements. E-Health Telecommun Syst Netw. 2012;1(02):19.

4. Roşu M, Paşca S. A WBAN-ECG approach for real-time longterm monitoring. In: 2013 8TH International symposium on advanced topics in electrical engineering (ATEE). IEEE, pp 1-6 2013.

5. Al Rasyid MUH, Lee BH, Sudarsono A. Implementation of body temperature and pulseoximeter sensors for wireless body area network. Sens Mater. 2015;27(8):727-32.

6. Kommey B, Kotey SD, Opoku D. Patient medical emergency alert system 2018.

7. Saha R, Biswas S (2018) Analytical study on data transmission in WBAN with user mobility support. In 2018 International 
Conference on Wireless Communications, Signal Processing and Networking (WiSPNET). IEEE, pp. 1-5.

8. Lee YD, Chung WY. Wireless sensor network based wearable smart shirt for ubiquitous health and activity monitoring. Sens Actuators B: Chem. 2009;140(2):390-5.

9. Burns A, Greene BR, McGrath MJ, O'Shea TJ, Kuris B, Ayer SM, Cionca V. SHIMMER ${ }^{\mathrm{TM}}$ _a wireless sensor platform for noninvasive biomedical research. IEEE Sens J. 2010;10(9):1527-34.

10. Chen CM. Web-based remote human pulse monitoring system with intelligent data analysis for home health care. Expert Syst Appl. 2011;38(3):2011-9.

11. Pawar PA. Heart rate monitoring system using IR base sensor and Arduino Uno. In: 2014 Conference on IT in Business, Industry and Government (CSIBIG) IEEE. pp. 1-3. 2014

12. Abdullah A, Ismael A, Rashid A, Abou-ElNour A, Tarique M. Real time wireless health monitoring application using mobile devices. Int J Comput Netw Commun (IJCNC). 2015;7(3):13-30.

13. Wannenburg J, Malekian R. Body sensor network for mobile health monitoring, a diagnosis and anticipating system. IEEE Sens J. 2015;15(12):6839-52.

14. Navya K, Murthy MBR. A Zigbee based patient health monitoring system. Int J Eng Res Appl. 2013;3(5):483-6.

15. Kumar R, Rajasekaran MP. An IoT based patient monitoring system using raspberry Pi. In: 2016 International conference on computing technologies and intelligent data engineering (ICCTIDE'16). IEEE, pp 1-4, 2016.

16. Mahmud MS, Wang H, Esfar-E-Alam AM, Fang H. A wireless health monitoring system using mobile phone accessories. IEEE Internet Things J. 2017;4(6):2009-18.

17. Sollu TS, Bachtiar M, Sooai AG. Patients' heart monitoring system based on wireless sensor network. In: IOP Conference Series: Materials Science and Engineering 2018;336(1):012009). IOP Publishing.

18. Ali NS, Alyasseri ZAA, Abdulmohson A. Real-time heart pulse monitoring technique using wireless sensor network and mobile application. Int J Electr Comput Eng. 2018;8(6):5118.

19. Benjemmaa A, Ltifi H, Ayed MB. Design of remote heart monitoring system for cardiac patients. In: International Conference on Advanced Information Networking and Applications. Springer, Cham, pp 963-976, 2019.

20. Ipswich D. Setting up a WAMP server on your windows desktop. Technology Now at Smashwords, 2011.

21. Greenspan J, Bulger B. MySQL/PHP database applications. New York: Wiley; 2001.
22. Mayalarp V, Limpaswadpaisarn N, Poombansao T, Kittipiyakul S. Wireless mesh networking with XBee. In: 2nd ECTI-Conference on Application Research and Development (ECTI-CARD 2010), Pattaya, Chonburi, Thailand, pp 10-12, 2010.

23. Sund-Levander M, Forsberg C, Wahren LK. Normal oral, rectal, tympanic and axillary body temperature in adult men and women: a systematic literature review. Scand J Caring Sci. 2002;16(2):122-8.

24. Juonala M, Magnussen CG, Berenson GS, Venn A, Burns TL, Sabin MA, Sun C. Childhood adiposity, adult adiposity, and cardiovascular risk factors. N Engl J Med. 2011;365:1876-85.

25. Mangat J, Standley T, Prevost A, Vasconcelos J, White P. A comparison of technologies used for estimation of body temperature. Physiol Meas. 2010;31(9):1105.

26. Fan K, Wang P, Zhuang S. Human fall detection using slow feature analysis. Multimed Tools Appl. 2019;78:9101-28. https:// doi.org/10.1007/s11042-018-5638-9.

27. Saha R, Naskar S, Biswas S, Saif S. Performance evaluation of energy-efficient routing with or without relay in medical body sensor network. Health Technol. 2019;9(5):805-15.

28. Zhang J. Intelligent temperature sensor DS18B20 and its application. Instrum Technol. 2010;4:68-70.

29. Megantoro P, Widjanarko A, Rahim R, Kunal K, Arfianto AZ. The design of digital liquid density meter based on Arduino. J. Robot Control. 2020;1(1):1-6.

30. Zhou Y, Sun C. DS18B20 Hardware connection and software programming. Doctoral dissertation, 2001.

31. Deshmukh AD, Shinde UB. A low cost environment monitoring system using raspberry Pi and arduino with Zigbee. In: 2016 International Conference on Inventive Computation Technologies (ICICT) (Vol. 3). IEEE, pp. 1-6, 2016.

32. Arduino SA. Arduino. Arduino LLC, 2015.

33. Jackson J. Microsoft robotics studio: a technical introduction. IEEE Robot Autom Mag. 2007;14(4):82-7.

34. Pattison T, Box D. Programming distributed applications with COM+ and Microsoft Visual Basic 6.0. Microsoft Press, 2000.

35. Agrawal S, Gupta RD. Development and comparison of open source based Web GIS frameworks on WAMP and Apache Tomcat Web Servers. Int Arch Photogramm Remote Sens Spat Inform Sci. 2014;40(4):1.

Publisher's Note Springer Nature remains neutral with regard to jurisdictional claims in published maps and institutional affiliations. 